\author{
UNIVERSIDADE DE SÃO PAULO \\ FACULDADE DE CIÊNCIAS FARMACÊUTICAS \\ Programa de Pós-Graduação em Fármaco e Medicamentos
}

\title{
Avaliação das atitudes de colaboração entre estudantes de graduação dos cursos de Farmácia e Medicina na Universidade de São Paulo
}

\section{Milenna Castanho}

\author{
Dissertação para obtenção do título de \\ Mestre
}

Orientador: Profa. Dra. Sílvia Storpirtis

São Paulo

Julho de 2018 


\author{
UNIVERSIDADE DE SÃO PAULO \\ FACULDADE DE CIÊNCIAS FARMACÊUTICAS \\ Programa de Pós-Graduação em Fármaco e Medicamentos
}

\title{
Avaliação das atitudes de colaboração entre estudantes de graduação dos cursos de Farmácia e Medicina na Universidade de São Paulo
}

\author{
Milenna Castanho \\ Versão corrigida da Dissertação conforme resolução CoPGr 6018. \\ Dissertação para obtenção do título de \\ Mestre \\ Orientador: Profa. Dra. Sílvia Storpirtis
}

São Paulo

Julho de 2018 
Autorizo a reproduçăo e divulgaçăo total ou parcial deste trabalho, por qualquer meio convencional ou eletronico, para fins de estudo e pesquisa, desde que citada a fonte.

Ficha Catalográfica elaborada eletronicamente pelo autor, utilizando o programa desenvolvido pela Seçăo Técnica de Informática do ICMC/USP e adaptado para a Divisăo de Biblioteca e Documentaçăo do Conjunto das Químicas da USP

Bibliotecária responsável pela orientaçăo de catalogaçăo da publicaçăo: Marlene Aparecida Vieira - CRB - 8/5562

$c 346 \mathrm{a}$

Castanho, Milenna

Avaliação das atitudes de colaboração entre estudantes de graduação dos cursos de Farmácia e Medicina na Universidade de São Paulo / Milenna Castanho. - São Paulo, 2018.

$$
53 \mathrm{p} \text {. }
$$

Dissertação (mestrado) - Faculdade de Ciências Farmacêticas da Universidade de São Paulo. Departamento de Farmácia.

Orientador: Storpirtis, Silvia

1. Educação Farmacêutica. 2. Relaçōes

interprofissionais. 3. Estudantes de Farmácia. 4.

Estudantes de Medicina. 5. Sistema Unico de Saúde.

I. T. II. Storpirtis, Silvia, orientador. 


\title{
Milenna Castanho
}

\section{Avaliação das atitudes de colaboração entre estudantes de graduação dos cursos de Farmácia e Medicina na Universidade de São Paulo}

\author{
Comissão Julgadora \\ da \\ Dissertação/Tese para obtenção do Título de Mestre/DOUTOR
}

Profa. Dra. Silvia Storpirts

orientador/presidente

10. examinador

2o. examinador

3o. examinador

São Paulo, de de 2018 . 


\section{Agradecimentos}

À Deus por todas as oportunidades que me foram dadas ao longo dos anos e pela perseverança de sempre manter o foco nos meus sonhos.

Aos meus pais Claudia e José Carlos por sempre acreditarem no meu potencial e apoiarem as minhas decisões por vezes não tão sensatas, mas que, com certeza, renderam frutos.

Aos meus irmãos, Rodrigo, Gabriela, Leticia e Leonardo que, cada um do seu jeito, contribuíram para que este dia fosse possível.

À minha prima Priscila que me levava às suas aulas da faculdade e plantou a semente farmacêutica em mim.

Aos demais familiares por cada palavra de incentivo desde a época de colégio para que eu seguisse firme com os meus estudos.

Aos meus superiores da Eurotrials, nas pessoas de Anderson, Joyce, Rodrigo e Ronaldo que não só me permitiram conciliar a rotina da empresa com a da pósgraduação, mas também foram os maiores encorajadores da mesma.

Aos meus dois times do coração que sempre foram um fator motivador durante a graduação e sem o apoio dos quais a pós-graduação não sairia do papel.

Aos meus amigos Isadora, Bianca, Leonardo e Mateus que me ajudaram nos períodos mais complicados do meu trabalho.

À minha co-orientadora Patricia Aguiar que sempre esteve presente desde a época do trabalho de conclusão de curso e foi muito importante para meu aprendizado como pesquisadora.

À minha orientadora Silvia Storpirts agradeço de todo coração por ter aceitado um trabalho desafiador em uma área com poucos estudos, principalmente em nossa faculdade, e por ter sempre me encorajado a primar pela excelência.

Ao secretário do Programa de pós-graduação em Fármaco e Medicamentos David que sempre se mostrou o mais prestativo possível para esclarecer dúvidas e ajudar os alunos com seus problemas. 
À Faculdade de Ciências Farmacêuticas da Universidade de São Paulo pela oportunidade de, não só, realizar este trabalho, mas por todo o conhecimento adquirido desde a graduação. Com toda a certeza, grande parte da profissional que sou hoje foi moldada nesta instituição.

À todos os estudantes da Faculdade de Ciências Farmacêuticas da Universidade de São Paulo e da Faculdade de Medicina da Universidade de São Paulo que disponibilizaram seu tempo para responder ao questionário da pesquisa. 


\section{ÍNDICE}

RESUMO

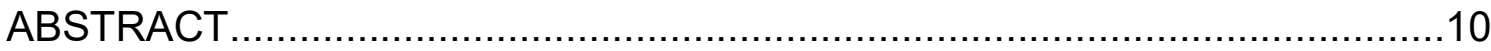

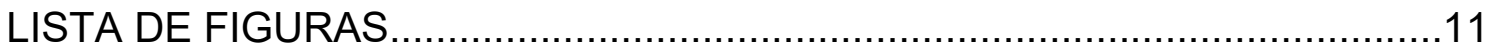

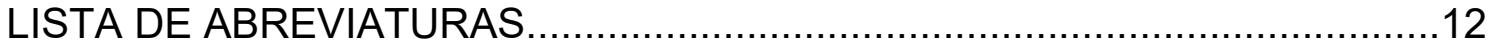

1.INTRODUÇÃO

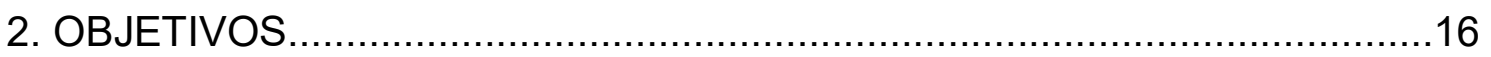

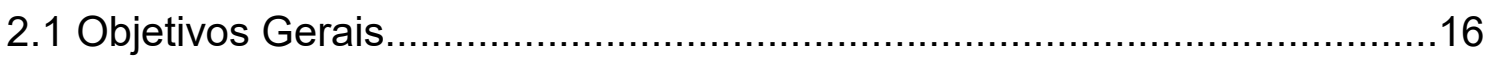

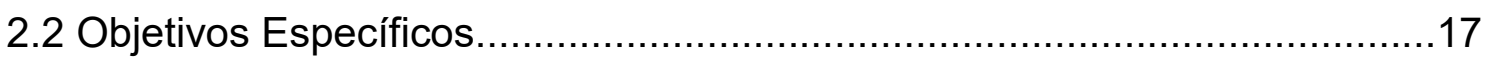

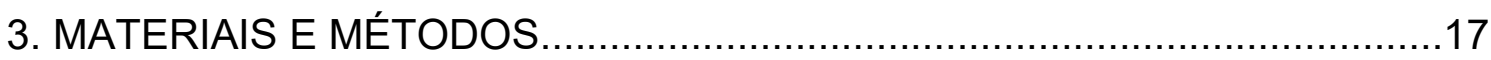

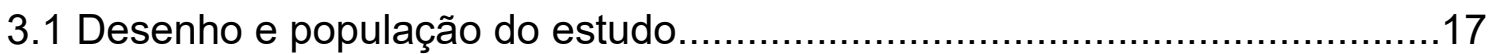

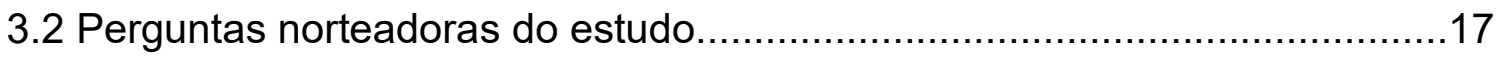

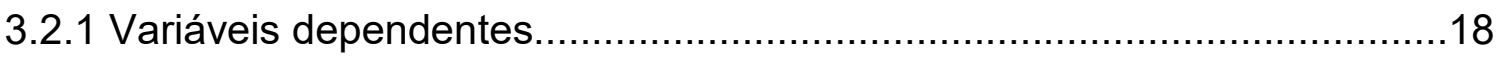

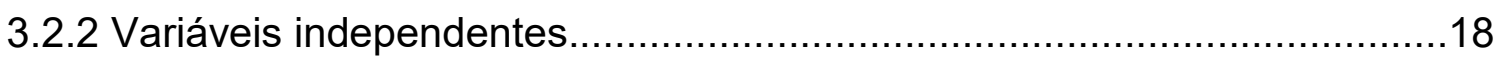

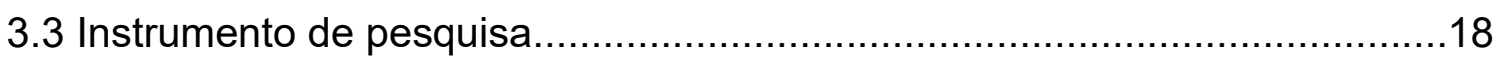

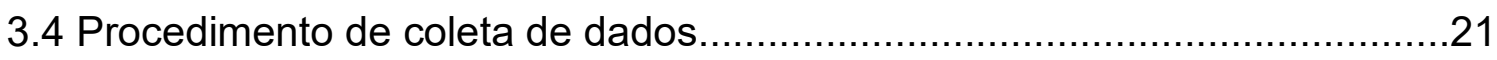

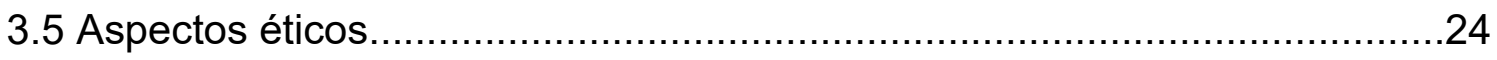

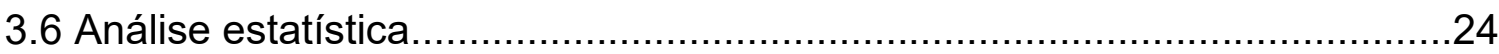

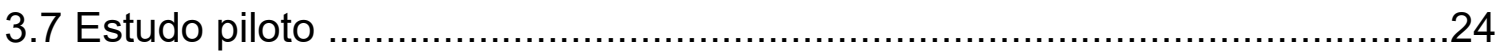

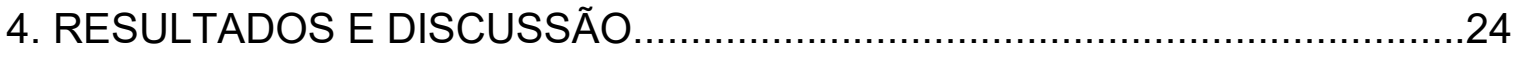

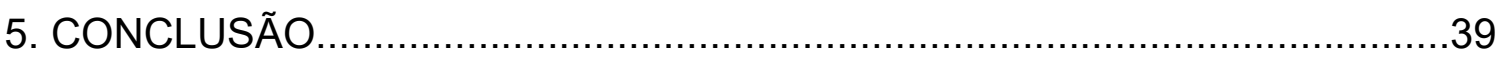

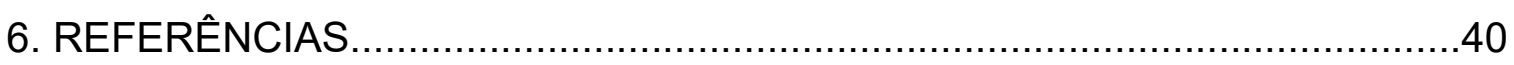

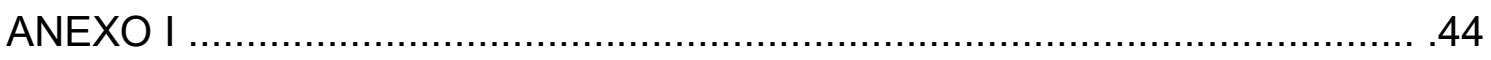

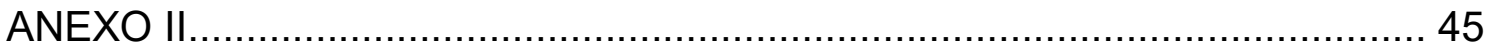

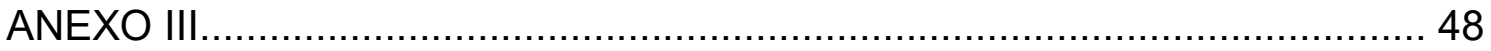

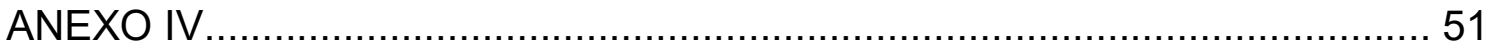




\section{RESUMO}

CASTANHO, M. Avaliação das atitudes de colaboração entre estudantes de graduação dos cursos de Farmácia e Medicina na Universidade de São Paulo. 2018. [55] f.

Palavras-chave: Educação Farmacêutica, Estudantes de Farmácia, Estudantes de Medicina, Relações interprofissionais, Sistema Único de Saúde.

A prática farmacêutica vem, ao longo dos anos, mudando o seu foco, uma vez que as mudanças de perfil epidemiológico, como a elevação da expectativa de vida, a diversidade de enfermidades crônicas, bem como a morbimortalidade associada ao uso de medicamentos e o aumento dos gastos com saúde, requerem acompanhamento prolongado de pacientes e abordagem integral que contemple as múltiplas dimensões da assistência à saúde dos usuários e da população em geral, com ênfase em prevenção e educação em saúde. Atributos importantes dos profissionais de saúde incluem, mas não estão limitados, à empatia cognitiva, a colaboração interprofissional e as orientações centradas no paciente. Instrumentos de pesquisa para medir cada um desses atributos foram projetados e validados em diferentes graus. O objetivo deste trabalho foi avaliar o grau de cooperação entre estudantes de graduação dos cursos de Farmácia e de Medicina da Universidade de São Paulo, Campus da Capital. Trata-se de um estudo do tipo transversal, quantitativo, com aplicação de questionário online construído e validado especificamente para avaliar o grau de cooperação entre estudantes de todos os anos de graduação dos cursos de Farmácia e de Medicina. Os dados foram coletados por meio do envio do questionário aos estudantes dos dois cursos, o qual contempla dados sócio-demográficos, contato prévio com a prática interprofissional e a versão validada para o português do instrumento "Scale of Attitudes Toward Pharmacist-Physician Collaboration". Foi realizada análise estatística empregandose métodos descritivos (média, mediana e desvio padrão) e inferenciais (Software $R$ - teste $\mathrm{t}$ de Student e ANOVA). Com o presente estudo, observou-se que, de maneira geral, os estudantes dos dois cursos são favoráveis às práticas interprofissionais, porém, os dados apontam que os estudantes de Farmácia se mostram mais favoráveis a estas práticas quando comparados aos de Medicina. São 
necessários mais estudos para aprofundar as causas das diferenças encontradas entre os dois grupos e no que diz respeito à relação das atividades de educação interprofissional e a percepção dos estudantes quanto à colaboração médicofarmacêutico. 


\section{ABSTRACT}

CASTANHO, M. Evaluation of collaboration attitudes among undergraduate students of Pharmacy and Medicine courses at the University of São Paulo. 2018. [55] f.

Keywords: Pharmaceutical Education, Pharmacy Students, Medical Students, Interprofessional Relations, Unified Health System.

Pharmaceutical practice has, over the years, changing its focus, since the epidemiological profile changes, such as increased life expectancy, the diversity of chronic diseases, as well as the morbidity and mortality associated with the use of drugs and the increase in health spending, require prolonged follow-up of patients and require comprehensive approach that addresses the multiple dimensions of health care users and the general population, with emphasis on prevention and health education. Important health professionals attributes include, but are not limited to cognitive empathy, interprofessional collaboration, and patient centered practice. Research tools to measure each of these attributes have been designed and validated to varying degrees. The objective of this study is to measure and evaluate the level of cooperation among undergraduate students of Pharmacy and Medicine courses at the University of São Paulo, Campus Capital. It was a transversal, quantitative study with online application of online questionnaire developed and validated specifically to evaluate the level of cooperation between students from all undergraduate years of Pharmacy and Medicine courses. Data was collected by sending the questionnaire to students from both courses. The questionnaire will be prepared on the basis of the Federal University of Sergipe tool and every student can respond to even just once. It was performed the statistical analysis employing descriptive methods (mean, median and standard deviation) and inferential (Software $R$ - Student's t-test and ANOVA). With the present study, it was observed that, in general, the students of the two courses are favorable to interprofessional practices, however the data indicate that the students of pharmacy are more favorable when compared to those of medicine. Further studies are necessary to look into the causes of the differences found between the two groups and also regarding the relation of the activities of interprofessional education and the students' perception regarding the physician-pharmacist collaboration. 


\section{Lista de Figuras}

Figura 1. Primeira seção do questionário.

Figura 2. Exemplo de programação para que não seja possível enviar o formulário sem a resposta.

Figura 3. Escala a ser empregada na pesquisa.

Figura 4. Distribuição dos estudantes pelo ano de graduação.

Figura 5. Respostas dos estudantes que participaram do estudo piloto. 


\section{Lista de Abreviaturas}

CEP - Comitê de Ética em Pesquisa

EAM - Eventos Adversos a Medicamentos

EIP - Educação Interprofissional em Saúde

RAM - Reação Adversa a Medicamentos

SUS - Sistema Único de Saúde 


\section{INTRODUÇÃO}

A prática farmacêutica vem, ao longo dos anos, mudando o seu foco. As mudanças de perfil epidemiológico, a elevação da expectativa de vida, o aumento da prevalência de enfermidades crônicas, a morbimortalidade associada ao uso de medicamentos e o aumento dos gastos com saúde requerem acompanhamento prolongado de pacientes com uma abordagem integral. Dessa forma, as práticas em saúde precisam se adaptar ao novo cenário e contemplar as múltiplas dimensões da assistência à saúde, dos usuários e da população em geral, com ênfase em prevenção de doenças e educação em saúde (PEDUZZI et al, 2013).

Historicamente, a colaboração interprofissional na assistência ao paciente entre os profissionais de saúde se fez presente nas guerras, principalmente, na Segunda Guerra Mundial, quando médicos, cirurgiões e equipes de enfermagem trabalharam em conjunto para tratar soldados feridos (VAN WINKLE, FJORTOFT, HOJAT, 2011).

Prestadores de cuidados de saúde consideram a colaboração e o trabalho em equipe como um componente importante de profissionalismo, levando à maior segurança e a melhores resultados para os pacientes. Dentre as colaborações interprofissionais atuais, a colaboração médico-farmacêutico resulta em melhoria de atendimento do paciente, menos interações medicamentosas (BALDWIN, 2007; MCDONOUGH, DOUCETTE, 2001) e menor incidência de erros de medicação (BROCK, DOUCETTE, 2004), além da utilização mais eficiente dos medicamentos, os quais levam a farmacoterapias mais eficazes e melhores resultados para os pacientes (SWEENEY, 2002).

A abordagem interprofissional do paciente é inerente ao cenário atual e já existem métodos de ensino, como a educação interprofissional (EIP), que aparecem como estratégia de ensino em vários países. Ferramentas como esta visam à formação de profissionais mais críticos, reflexivos, capazes de trabalhar em equipe e de aprenderem juntos com as outras profissões (SILVA, 2011). Este conceito não é novo, trata-se de um fenômeno global que recebeu atenção pela primeira vez quando a Organização Mundial de Saúde (OMS) publicou o documento intitulado "Learning to Work Together for Health" (OMS, 1988). 
Posteriormente, em 2006, a 59a Assembleia Mundial de Saúde respondeu à crise de recursos humanos para a saúde com a implementação da Resolução WHA59.23, que trouxe a recomendação do rápido aumento da produção de força de trabalho em saúde. Entre as estratégias descritas no documento destacam-se as "abordagens inovadoras de ensino em países industrializados e em desenvolvimento", abordagens que incluem ferramentas de ensino com enfoques multidisciplinares (OMS, 2010).

Já no documento "Marco para Ação em Educação Interprofissional e Prática Colaborativa", publicado em 2010 pela OMS, há o reconhecimento de que muitos sistemas de saúde no mundo estão fragmentados e com dificuldades para gerenciar as necessidades de saúde não atendidas. Assim, a força de trabalho de saúde atual e futura é desafiada a prestar serviços de saúde frente a enfermidades cada vez mais complexas. Estudos mostram que conforme esses profissionais de saúde percorrem o sistema surgem oportunidades para adquirir experiência interprofissional. Tais oportunidades podem ser aproveitadas para desenvolver as habilidades necessárias para se tornarem parte da força de trabalho em saúde de forma colaborativa, preparada para a prática de saúde demandada pelo cenário atual (OMS, 2010).

Cada profissional possui um conjunto de características individuais que alteram a sua disponibilidade para aceitar as mudanças e os riscos envolvidos no desenvolvimento de uma colaboração. Tais características podem ser a demografia, a educação e a idade. Por exemplo, os profissionais mais jovens que passaram por experiências de educação interprofissional tendem a ser mais receptivos à colaboração farmacêutico-médico (HAXBY, WEART e GOODMAN, 1988). Em contrapartida, alguns médicos mais velhos apresentaram menor apoio para a expansão do papel que os farmacêuticos desempenham na prestação de serviços clínicos (HAXBY, WEART e GOODMAN, 1988).

A proximidade entre os profissionais - geograficamente, organizacionalmente e/ou socialmente - é outra característica importante no contexto dessa colaboração. Em locais onde farmacêuticos e médicos estão em estreita proximidade, oportunidades para interagir aumentam, porque eles podem compartilhar um mesmo 
espaço físico, ser parte do mesmo grupo de gestão, e participar de negócios e funções sociais. Essas circunstâncias podem aumentar o número de interações nas quais os profissionais vivenciam a abordagem de cada um para o atendimento ao paciente, aumentando o seu nível de conforto com a competência clínica do outro (MCDONOUGH, DOUCETTE, 2001).

Atributos importantes dos profissionais de saúde incluem, mas não estão limitados, à empatia cognitiva, à colaboração interprofissional e às orientações centradas no paciente. Entretanto, a mensuração destes atributos depende de fatores de difícil quantificação e controle, o que por muito tempo dificultou uma avaliação técnica desses comportamentos. Atualmente estão disponíveis diversos instrumentos de pesquisa para medir cada um desses atributos, projetados e validados de diferentes maneiras (VAN WINKLE et al., 2012).

A educação interprofissional nas faculdades de medicina e de farmácia é projetada para melhorar as habilidades de médicos e farmacêuticos para o trabalho em equipes de saúde interprofissionais (ZILLICH et al, 2006). Estes esforços educacionais são para garantir que todos os profissionais de saúde usem efetivamente a sua formação e conhecimentos especializados para otimizar o atendimento ao paciente e melhorar os resultados terapêuticos. A relação de colaboração entre farmacêuticos e médicos é necessária, mais do que nunca, por causa dos rápidos avanços nas ciências médicas e farmacêuticas, a ocorrência de interações complexas entre fármacos, o aumento dos custos de morbidade relacionada ao uso de medicamentos, maior possibilidade de erros médicos, além do rápido aumento dos custos de saúde (VAN WINKLE, FJORTOFT, HOJAT, 2011).

No Brasil, contudo, pouco se conhece sobre as atitudes colaborativas entre os estudantes de medicina e de farmácia. Logo, devido à crescente demanda para mudança na maneira como os pacientes são assistidos quando adentram o sistema de saúde, torna-se necessária a realização de mais estudos sobre a formação dos profissionais de saúde, de modo a possibilitar o delineamento de estratégias direcionadas à melhoria do cuidado integral em saúde. Tal fato é especialmente importante no momento atual em que estão sendo implementadas as novas 
diretrizes curriculares para cursos de graduação na área da saúde (MINISTÉRIO DA EDUCAÇÃO, 2014; MINISTÉRIO DA EDUCAÇÃO, 2017).

Cabe ressaltar que a Universidade de São Paulo vem discutindo o tema "Educação" dentro dos cursos da área de saúde. Com a criação da disciplina optativa livre "Práticas, formação e educação interprofissional em saúde", pela Escola de Enfermagem da USP criou-se a oportunidade para os estudantes dos cursos de saúde se aproximarem deste tema.

Na Faculdade de Ciências Farmacêuticas da USP esse assunto, apesar de ser pouco discutido, conta com uma disciplina criada pela Professora Dra. Ligia Ferreira Gomes denominada "Prática Multiprofissional em Atenção Básica à Saúde". Tal disciplina tem como objetivo, segundo a ementa: 1- Oferecer a estudantes de cursos da área da saúde a oportunidade de experiência vivencial do cotidiano da Unidade Básica de Saúde para a compreensão do funcionamento do Sistema Único de Saúde, através da imersão na dinâmica dos serviços para o desenvolvimento de atividades de promoção à saúde em grupos multiprofissionais com estrutura tutorial. 2- Ampliar a percepção do estudante vocacionado para o trabalho na área de saúde a respeito das potencialidades, responsabilidades e demandas específicas da própria formação profissional para o exercício da interdisciplinaridade (GOMES, 2018).

Nesse contexto foi observada a necessidade de estudar o cenário dentro da Universidade de São Paulo no que se refere à cooperação dos profissionais de saúde formados na Instituição e, para este trabalho específico, entre os graduandos de Farmácia e de Medicina do Campus São Paulo.

\section{OBJETIVOS}

\subsection{Geral}

Avaliar atitude de cooperação entre os estudantes de graduação dos cursos de Farmácia e de Medicina na Universidade de São Paulo, Campus São Paulo. 


\subsection{Específicos}

2.2.1 Aplicar o questionário via Internet para os estudantes dos cursos de graduação de Farmácia e de Medicina da Universidade de São Paulo, Campus São Paulo.

2.2.2 Analisar os dados obtidos a fim de avaliar qual a concepção dos estudantes em relação à cooperação médico-farmacêutico.

\section{MATERIAIS E MÉTODOS}

\subsection{Desenho e população do estudo}

Trata-se de um estudo do tipo transversal, quantitativo, com aplicação de questionário online construído e validado especificamente para avaliar o grau de cooperação entre os estudantes de graduação dos cursos de Farmácia e de Medicina da Universidade de São Paulo, Campus da Capital.

A Faculdade de Medicina possui aproximadamente 1050 alunos ativos na graduação, enquanto que a Faculdade de Ciências Farmacêuticas possui aproximadamente 900 .

\subsection{Perguntas norteadoras do estudo}

Para investigar a concepção dos estudantes dos referidos cursos em relação à cooperação entre eles duas perguntas norteadoras foram propostas:

- Os estudantes dos cursos de Farmácia e de Medicina da Universidade de São Paulo acreditam na cooperação entre as duas profissões?

- Existiria relação entre o ano da graduação em que o estudante se encontra e a sua concepção sobre a colaboração entre o Farmacêutico e o Médico? 


\subsubsection{Variáveis dependentes}

Foi designada uma variável dependente para o estudo: o grau de cooperação entre estudantes de graduação dos cursos de Farmácia e de Medicina no decorrer dos cursos.

\section{Colaboração Médico-Farmacêutico}

Para avaliar o grau de cooperação entre estudantes de graduação dos cursos de Farmácia e de Medicina foi aplicado um questionário validado com perguntas que permeiam a visão que os estudantes têm de sua profissão (Farmácia ou Medicina) e como eles veem a colaboração com a outra profissão em estudo (Farmácia ou Medicina).

\subsubsection{Variáveis independentes}

As variáveis independentes analisadas foram:

- Idade;

- Gênero;

- Curso de graduação em curso;

- Ano da graduação em curso;

- Contato prévio com a prática interprofissional.

\subsection{Instrumento de pesquisa}

As atitudes colaborativas entre os estudantes foram mensuradas por meio da ferramenta "Scale of Attitudes Toward Pharmacist-Physician Collaboration", a qual foi desenvolvida por Van Winkle et al. (2011) e validada para o português por pesquisadores da Universidade Federal de Sergipe (dissertação defendida no primeiro semestre de 2016, com artigo publicado em 30 de junho de 2017 no periódico "Pharmacy Practice”) (CUNHA et al, 2016; CUNHA et al. 2017). 
A escala empregada neste instrumento apresenta o total de 16 afirmações/itens (Quadro 1), com uma variação de 1 a 4 pontos, dependendo do quanto o estudante concorda com a afirmação (quanto maior o número, maior o grau de concordância com a afirmação em questão). 


\section{Afirmações}

1- Um médico deveria ser visto como um colaborador e colega do farmacêutico em vez de seu superior

2- Os farmacêuticos estão qualificados para avaliar e responder às necessidades farmacoterapêuticas dos pacientes

3- Durante a sua formação, os estudantes de Farmácia e Medicina deveriam ser envolvidos no trabalho de equipe para compreender os seus respectivos papéis

4- Os farmacêuticos podem contribuir na tomada de decisões sobre as interações medicamentosas que podem afetar os pacientes

5- Os farmacêuticos deveriam ser responsáveis pelos medicamentos que eles fornecem aos pacientes

6- Há muitas áreas em comum de responsabilidade entre farmacêuticos e médicos quanto à farmacoterapia dos pacientes

7- Os farmacêuticos têm conhecimento especializado para aconselhar os pacientes sobre a farmacoterapia

8- Tanto os farmacêuticos quanto os médicos deveriam contribuir nas decisões sobre o tipo e a dosagem dos medicamentos fornecidos aos pacientes

9- A função principal do farmacêutico é atender a prescrição do médico sem questionamento

10- Os farmacêuticos deveriam estar envolvidos na tomada de decisões sobre políticas de medicamentos em serviços de farmácias/hospitais dos quais o seu trabalho depende

11- Os farmacêuticos, assim como os médicos, deveriam ter responsabilidade pelo monitoramento dos efeitos dos medicamentos em seus pacientes

12- Os farmacêuticos deveriam esclarecer uma prescrição médica quando perceberem que esta pode causar efeitos prejudiciais ao paciente

13- Médicos e farmacêuticos deveriam ser educados para estabelecer relações de colaboração

14- Os médicos deveriam consultar os farmacêuticos para ajudar os pacientes com reações adversas ou refratários à farmacoterapia

15- Os médicos deveriam ser conscientizados de que os farmacêuticos podem ajudar no fornecimento correto da farmacoterapia

16- Relações interprofissionais entre médicos e farmacêuticos deveriam ser incluídas em seus programas de formação profissional

Quadro 1. Questionário proposto aos estudantes de Farmácia e de Medicina (CUNHA et al. 2017). 


\subsection{Procedimento de coleta de dados}

Após a aprovação do projeto pelo CEP da FCF-USP foi possível desenvolver o questionário online usando a plataforma do 'Formulários Google' (Disponível em: https://docs.google.com/forms/d/e/1FAlpQLSeTnUJ8bl PNT7jiVftc8ZOKyuv4qJzjlkp 9FBTKq A37FsAw/viewform?c=0\&w=1) (Figuras 1, 2 e 3).

As perguntas do questionário tiveram marcadores de modo a não permitir a conclusão da avaliação enquanto todas as questões não tivessem sido respondidas.

\section{Avaliação das atitudes de colaboração entre estudantes de graduação dos cursos de Farmácia e Medicina na Universidade de São Paulo}

Questionário para a projeto de mestrado de Milenna Castanho PRÓXIMA

Figura 1: Primeira seção do questionário. 
Seu consentimento: eu declaro estar informado(a) das condições de participação na pesquisa " Avaliação das atitudes de colaboração entre estudantes de graduação dos cursos de Farmácia e Medicina na Universidade de São Paulo " e ter livre interesse em participar. Declaro também estar informado de todas as condições para participação. Eu reconheço que minha participação é anônima e as minhas informações fornecidas serão estritamente confidenciais e usadas apenas para fim de pesquisa científica. *

Aceito

Não aceito

Esta pergunta é obrigatória

VOLTAR PRÓXIMA

Figura 2: Exemplo de programação para que o questionário não pudesse ser concluído sem as respostas. 


\section{Avaliação das atitudes de colaboração entre estudantes de graduação dos cursos de Farmácia e Medicina na Universidade de São Paulo}

*Obrigatório

\section{ESCALA DE ATITUDES SOBRE COLABORAÇÃO MÉDICO- FARMACÊUTICO}

INSTRUÇÕES: Por favor, indique o quanto você concorda ou discorda com cada uma das seguintes afirmações circulando o número apropriado na escala de 4 pontos (1- Discordo fortemente, 2- Discordo, 3-Concordo, 4-Concordo fortemente).

$\star$

1 - Discordo fortemente

Um médico deveria ser visto como um colaborador e

colega do farmacêutico em vez de seu superior
2 - Discordo 3 - Concordo

4 - Concordo Fortemente

Figura 3: Escala empregada na pesquisa.

Os dados foram coletados por meio do envio do questionário online (Anexo I) ao e-mail USP dos estudantes dos dois cursos, obtido por meio do contato com o Serviço de Graduação de ambas as Faculdades. Os estudantes responderam ao questionário de maneira voluntária, sem nenhuma obrigatoriedade, sendo que cada aluno poderia responde-lo apenas uma vez.

O questionário foi disponibilizado por meio da página https://www. docs.google.com/forms. Além disso, a divulgação do projeto foi realizada nas redes sociais (Facebook® e WhatsApp®). 


\subsection{Aspectos éticos}

A realização do projeto seguiu os parâmetros éticos estabelecidos pela Resolução 466/12, do Conselho Nacional de Saúde.

O projeto foi submetido para análise do Comitê de Ética em Pesquisa (CEP) da Faculdade de Ciências Farmacêuticas da Universidade de São Paulo (FCF-USP) e aprovado em 12 de dezembro de 2016. Foi enviado à Comissão de Graduação da Faculdade de Medicina da USP (FMUSP) e aprovado em 06 de outubro de 2017.

\subsection{Análise estatística}

As análises estatísticas foram realizadas por um estatístico com a sistematização dos dados obtidos a partir do instrumento de coleta de dados, comparando-se os resultados obtidos entre os dois grupos de estudo (estudantes de Farmácia de e Medicina), avaliando as diferentes respostas dentro dos dois grupos, de acordo com o ano da graduação em que os estudantes se encontram e o contato prévio com a prática interprofissional. Foi realizada análise estatística empregando-se métodos descritivos (média, mediana e desvio-padrão) e inferenciais (Software R - teste t de Student e ANOVA).

\subsection{Estudo piloto}

Durante o mês de janeiro de 2017 foi realizado um estudo piloto com o objetivo de testar e avaliar o questionário a ser utilizado para a avaliação da colaboração médico-farmacêutico, bem como propor alterações na proposta inicial, se necessário.

\section{RESULTADOS E DISCUSSÃO}

Em relação ao estudo piloto, o questionário foi respondido por 17 estudantes de Farmácia, todos do gênero feminino. A plataforma utilizada se mostrou uma 
ferramenta adequada para o estudo, entregando os dados obtidos na forma de gráficos e uma planilha de Excel®.

Os dados obtidos mostram que os estudantes que participaram possuem uma média de idade igual a 22,6 anos e, em sua maioria, estão na segunda metade do curso $\left(4^{\circ}, 5^{\circ}\right.$ e $6^{\circ}$ ano) (Figura 4$)$.

\section{Ano do curso}
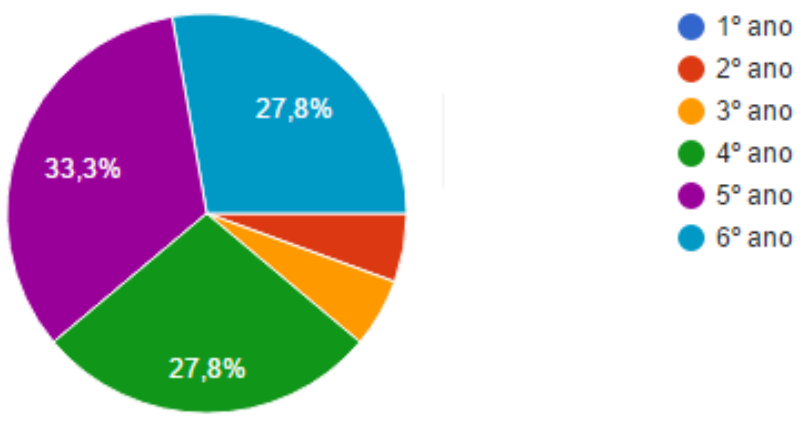

Figura 4: Distribuição dos estudantes pelo ano de graduação.

Com relação às experiências com educação interprofissional, das 17 respostas obtidas, apenas quatro estudantes tiveram contato prévio com experiências interprofissionais, sendo três deles por meio do estágio no Hospital Universitário da USP e um pela participação na Jornada Universitária da Saúde e Jornada Científica dos Acadêmicos de Farmácia-Bioquímica.

As respostas obtidas para a "Escala de Atitudes sobre Colaboração MédicoFarmacêutico" (Figura 5) mostraram que, em sua totalidade, os estudantes de Farmácia acreditam fortemente que durante sua formação os estudantes de Farmácia e de Medicina deveriam ser envolvidos em atividades em equipe para compreender seus respectivos papéis (Item 13) e que os médicos deveriam ser conscientizados de que os farmacêuticos podem ajudar no fornecimento correto da farmacoterapia (Item 14). 
Outro ponto a ser ressaltado são as respostas obtidas para o Item 9 do questionário: A função principal do farmacêutico é atender a prescrição do médico sem questionamento. Em sua totalidade, os estudantes de Farmácia discordaram desta afirmação, sendo que a maioria respondeu à afirmação com "Discordo Fortemente". Além disso, os estudantes de Farmácia consideram que o seu papel para com os pacientes também se refere a ajudar na tomada de decisão sobre a farmacoterapia, conforme pode ser observado pelas respostas obtidas para o Item 4 do questionário. 
16. Relações interprofissionais entre médicos e farmacêuticos deveriam ser incluídas em seus programas de formação profissional

15.Os médicos deveriam ser conscientizados de que os farmacêuticos podem ajudar no fornecimento correto da farmacoterapia

14. Os médicos deveriam consultar os farmacêuticos para ajudar os pacientes com reações adversas ou refratários à farmacoterapia

13. Médicos e farmacêuticos deveriam ser educados para estabelecer relações de colaboração

12. Os farmacêuticos deveriam esclarecer uma prescrição médica quando perceberem que esta pode causar efeitos prejudiciais ao paciente

11. Os farmacêuticos, assim como os médicos, deveriam ter responsabilidade pelo monitoramento dos efeitos dos medicamentos em seus pacientes 10. Os farmacêuticos deveriam estar envolvidos na tomada de decisões sobre políticas de medicamentos em serviços de farmácias/hospitais dos quais o seu...

9. A função principal do farmacêutico é atender a prescrição do médico sem questionamento

8. Tanto os farmacêuticos quanto os médicos deveriam contribuir nas decisões sobre o tipo e a dosagem dos medicamentos fornecidos aos pacientes

7. Os farmacêuticos tem conhecimento especializado para aconselhar os pacientes sobre a farmacoterapia

6. Há muitas áreas em comum de responsabilidade entre farmacêuticos e médicos quanto à

farmacoterapia dos pacientes

5. Os farmacêuticos deveriam ser responsáveis pelos medicamentos que eles fornecem aos pacientes

4. Os farmacêuticos podem contribuir na tomada de decisões sobre as interações medicamentosas que podem afetar os pacientes

3. Durante a sua formação, os estudantes de Farmácia e Medicina deveriam ser envolvidos no trabalho de equipe para compreender os seus respectivos papéis 2. Os farmacêuticos estão qualificados para avaliar e responder às necessidades farmacoterapêuticas dos pacientes

1.Um médico deveria ser visto como um colaborador e colega do farmacêutico em vez de seu superior

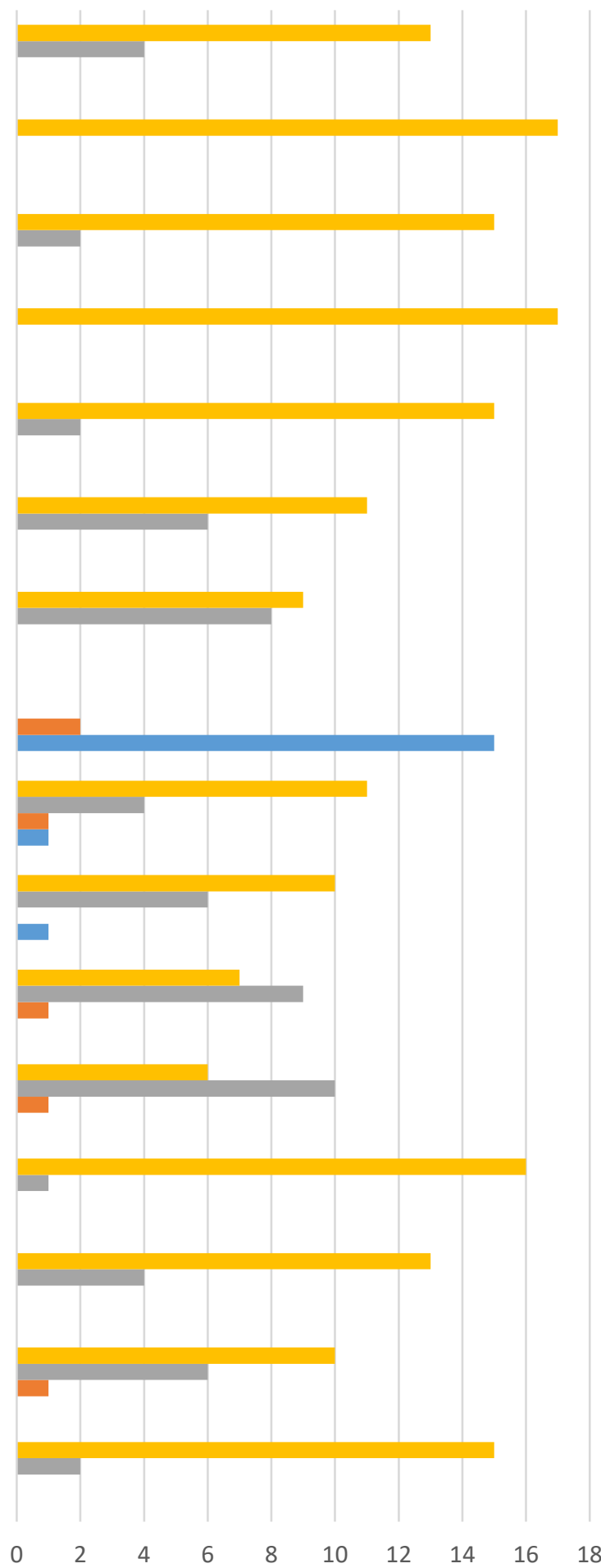

$\square 4$ - Concordo Fortemente $\quad 3$ - Concordo

2 - Discordo

1 - Discordo fortemente

Figura 5: Gráfico com as respostas dos estudantes que participaram do estudo piloto. 
A realização do estudo piloto foi importante para verificar a aplicabilidade da ferramenta, sendo que não houve necessidade de alterar qualquer aspecto de formatação do formulário elaborado. A única alteração realizada foi colocar alternativas fixas a serem selecionadas para os participantes para a questão de participação em atividades interprofissionais.

Assim sendo, o questionário foi enviado aos alunos no dia 08 de outubro de 2017 (após a aprovação da Comissão de Graduação da Faculdade de Medicina da USP), sendo que foram feitos lembretes quinzenais em outubro e semanais de novembro de 2017 a março de 2018. Foram obtidas 164 respostas, cuja distribuição se encontra na Tabela 1.

Tabela 1. Distribuição do retorno do questionário

\begin{tabular}{lccc|}
\hline Curso & Enviados & Recebidos & $\%$ de Retorno \\
\hline Medicina & 1050 & 60 & $5,7 \%$ \\
Farmácia & 900 & 104 & $11,6 \%$ \\
\hline Total & $\mathbf{1 9 5 0}$ & $\mathbf{1 6 4}$ & $\mathbf{8 , 4} \%$ \\
\hline
\end{tabular}

Cabe ressaltar que o número mínimo de participantes esperado era de, aproximadamente, 585 estudantes (30\% de respostas). Segundo estudos realizados sobre o uso de questionários online, as taxas de resposta deste meio de envio são mais baixas do que quando estes questionários são aplicados de maneira presencial. Em suas pesquisas, os dois estudos utilizados como base no presente projeto, Vieira, Castro e Júnior (2010) e Gonçalves (2008) obtiveram taxa de resposta de 25,2 e $6,3 \%$, respectivamente.

Acredita-se que não foi possível alcançar o número esperado de participantes pelas seguintes razões: demora na aprovação na Faculdade de Medicina da USP, o que fez com que os questionários fossem enviados para os alunos apenas em outubro de 2017; neste período, a Faculdade de Medicina entrou em greve devido aos problemas relacionados ao Hospital Universitário da USP, dificultando o acesso aos alunos. 
Foram levantados também dados demográficos que permitissem avaliar de maneira mais completa o perfil dos estudantes. O número de respostas obtidas ao questionário segundo gênero, curso e ano, assim como as distribuições por essas variáveis encontram-se na Tabela 2.

Os estudantes do curso de Farmácia respondem por $63 \%$ da amostra e a média de idade foi de 22,9 anos (DP=4,01) (Figura 6).

Tabela 2. Distribuição dos estudantes segundo gênero, curso e ano do curso.

\begin{tabular}{lcc}
\hline \multicolumn{1}{c}{ Variáveis } & Número & $\%$ \\
\hline $\begin{array}{c}\text { Gênero } \\
\text { Feminino }\end{array}$ & 109 & 66,5 \\
Masculino & 55 & 33,5 \\
\hline Curso de graduação & & \\
Farmácia & 104 & 63,4 \\
Medicina & 60 & 36,6 \\
\hline Ano do curso & & \\
$1^{\circ}$ ano & 22 & 13,4 \\
$2^{\circ}$ ano & 29 & 17,7 \\
$3^{\circ}$ ano & 22 & 13,4 \\
$4^{\circ}$ ano & 33 & 20,1 \\
$5^{\circ}$ ano & 33 & 20,1 \\
$6^{\circ}$ ano & 25 & 15,2 \\
\hline
\end{tabular}

Fonte: Dados elaborados pelo autor.

\section{Farmácia}

Medicina 
Figura 6: Distribuição dos estudantes do curso de farmácia e de medicina segundo gênero. 
Na Tabela 3 estão apresentados os dados relacionados às respostas dos estudantes de Farmácia e Medicina para as 16 afirmações do questionário.

Tabela 3. Distribuição das respostas as afirmações dos estudantes segundo o curso

\begin{tabular}{|c|c|c|c|c|c|c|c|c|c|c|c|c|c|c|c|c|c|c|c|c|c|c|c|c|}
\hline \multirow{3}{*}{$\begin{array}{c}\text { Afirmações } \\
\text { (variáveis) }\end{array}$} & \multicolumn{8}{|c|}{ Total } & \multicolumn{8}{|c|}{ Farmácia } & \multicolumn{8}{|c|}{ Medicina } \\
\hline & \multicolumn{2}{|c|}{$\begin{array}{c}1- \\
\text { Discordo } \\
\text { fortemente }\end{array}$} & \multicolumn{2}{|c|}{$\begin{array}{c}2 \text { - } \\
\text { Discordo }\end{array}$} & \multicolumn{2}{|c|}{$\begin{array}{c}3 \text { - } \\
\text { Concordo }\end{array}$} & \multicolumn{2}{|c|}{$\begin{array}{c}4 \text { - } \\
\text { Concordo } \\
\text { fortemente }\end{array}$} & \multicolumn{2}{|c|}{$\begin{array}{c}1- \\
\text { Discordo } \\
\text { fortemente } \\
\end{array}$} & \multicolumn{2}{|c|}{$\begin{array}{c}2- \\
\text { Discordo }\end{array}$} & \multicolumn{2}{|c|}{$\begin{array}{c}3 \text { - } \\
\text { Concordo }\end{array}$} & \multicolumn{2}{|c|}{$\begin{array}{c}4 \text { - Concordo } \\
\text { fortemente }\end{array}$} & \multicolumn{2}{|c|}{$\begin{array}{c}1- \\
\text { Discordo } \\
\text { fortemente }\end{array}$} & \multicolumn{2}{|c|}{$\begin{array}{c}2 \text { - } \\
\text { Discordo }\end{array}$} & \multicolumn{2}{|c|}{$\begin{array}{c}3- \\
\text { Concordo }\end{array}$} & \multicolumn{2}{|c|}{$\begin{array}{l}4 \text { - Concordo } \\
\text { fortemente }\end{array}$} \\
\hline & $\mathrm{n}$ & $\%$ & $n$ & $\%$ & $n$ & $\%$ & $\mathrm{n}$ & $\%$ & $\mathrm{n}$ & $\%$ & $\mathrm{n}$ & $\%$ & $n$ & $\%$ & $n$ & $\%$ & $n$ & $\%$ & $\mathrm{n}$ & $\%$ & $n$ & $\%$ & $\mathrm{n}$ & $\%$ \\
\hline 1 & 2 & $1,2 \%$ & 6 & $3,7 \%$ & 26 & $15,9 \%$ & 130 & $79,3 \%$ & 1 & $1,0 \%$ & 0 & $0,0 \%$ & 10 & $9,6 \%$ & 93 & $89,4 \%$ & 1 & $1,7 \%$ & 6 & $10,0 \%$ & 16 & $26,7 \%$ & 37 & $61,7 \%$ \\
\hline 2 & 3 & $1,8 \%$ & 28 & $17,1 \%$ & 68 & $41,5 \%$ & 65 & $39,6 \%$ & 1 & $1,0 \%$ & 6 & $5,8 \%$ & 41 & $39,4 \%$ & 56 & $53,8 \%$ & 2 & $3,3 \%$ & 22 & $36,7 \%$ & 27 & $45,0 \%$ & 9 & $15,0 \%$ \\
\hline 3 & 1 & $0,6 \%$ & 3 & $1,8 \%$ & 37 & $22,6 \%$ & 123 & $75,0 \%$ & 1 & $1,0 \%$ & 0 & $0,0 \%$ & 20 & $19,2 \%$ & 83 & $79,8 \%$ & 0 & $0,0 \%$ & 3 & $5,0 \%$ & 17 & $28,3 \%$ & 40 & $66,7 \%$ \\
\hline 4 & 1 & $0,6 \%$ & 1 & $0,6 \%$ & 39 & $23,8 \%$ & 123 & $75,0 \%$ & 1 & $1,0 \%$ & 0 & $0,0 \%$ & 17 & $16,3 \%$ & 86 & $82,7 \%$ & 0 & $0,0 \%$ & 1 & $1,7 \%$ & 22 & $36,7 \%$ & 37 & $61,7 \%$ \\
\hline 5 & 4 & $2,4 \%$ & 34 & $20,7 \%$ & 67 & $40,9 \%$ & 59 & $36,0 \%$ & 1 & $1,0 \%$ & 9 & $8,7 \%$ & 45 & $43,3 \%$ & 49 & $47,1 \%$ & 3 & $5,0 \%$ & 25 & $41,7 \%$ & 22 & $36,7 \%$ & 10 & $16,7 \%$ \\
\hline 6 & 2 & $1,2 \%$ & 10 & $6,1 \%$ & 69 & $42,1 \%$ & 83 & $50,6 \%$ & 1 & $1,0 \%$ & 3 & $2,9 \%$ & 41 & $39,4 \%$ & 59 & $56,7 \%$ & 1 & $1,7 \%$ & 7 & $11,7 \%$ & 28 & $46,7 \%$ & 24 & $40,0 \%$ \\
\hline 7 & 5 & $3,0 \%$ & 15 & $9,1 \%$ & 71 & $43,3 \%$ & 73 & $44,5 \%$ & 3 & $2,9 \%$ & 3 & $2,9 \%$ & 41 & $39,4 \%$ & 57 & $54,8 \%$ & 2 & $3,3 \%$ & 12 & $20,0 \%$ & 30 & $50,0 \%$ & 16 & $26,7 \%$ \\
\hline 8 & 4 & $2,4 \%$ & 12 & $7,3 \%$ & & $45,1 \%$ & 74 & $45,1 \%$ & 1 & $1,0 \%$ & 2 & $1,9 \%$ & 40 & $38,5 \%$ & 61 & $58,7 \%$ & 3 & $5,0 \%$ & 10 & $16,7 \%$ & 34 & $56,7 \%$ & 13 & $21,7 \%$ \\
\hline 9 & 117 & $71,3 \%$ & 44 & $26,8 \%$ & 3 & $1,8 \%$ & 0 & $0,0 \%$ & 88 & $84,6 \%$ & 16 & $15,4 \%$ & 0 & $0,0 \%$ & 0 & $0,0 \%$ & 29 & $48,3 \%$ & 28 & $46,7 \%$ & 3 & $5,0 \%$ & 0 & $0,0 \%$ \\
\hline 10 & 1 & $0,6 \%$ & 3 & $1,8 \%$ & & $29,3 \%$ & 112 & $68,3 \%$ & 1 & $1,0 \%$ & 1 & $1,0 \%$ & 22 & $21,2 \%$ & 80 & $76,9 \%$ & 0 & $0,0 \%$ & 2 & $3,3 \%$ & 26 & $43,3 \%$ & 32 & $53,3 \%$ \\
\hline 11 & 4 & $2,4 \%$ & 18 & $11,0 \%$ & 56 & $34,1 \%$ & 86 & $52,4 \%$ & 1 & $1,0 \%$ & 5 & $4,8 \%$ & 31 & $29,8 \%$ & 67 & $64,4 \%$ & 3 & $5,0 \%$ & 13 & $21,7 \%$ & 25 & $41,7 \%$ & 19 & $31,7 \%$ \\
\hline 12 & 1 & ,6\% & 5 & $3,0 \%$ & 35 & $21,3 \%$ & 123 & $75,0 \%$ & 1 & $1,0 \%$ & 5 & $4,8 \%$ & 14 & $13,5 \%$ & 84 & $80,8 \%$ & 0 & $0,0 \%$ & 0 & $0,0 \%$ & 21 & $35,0 \%$ & 39 & $65,0 \%$ \\
\hline 13 & 1 & $0,6 \%$ & 1 & $0,6 \%$ & 25 & $15,2 \%$ & 137 & $83,5 \%$ & 1 & $1,0 \%$ & 1 & $1,0 \%$ & 8 & $7,7 \%$ & 94 & $90,4 \%$ & 0 & $0,0 \%$ & 0 & $0,0 \%$ & 17 & $28,3 \%$ & 43 & $71,7 \%$ \\
\hline 14 & 3 & $1,8 \%$ & 8 & $4,9 \%$ & 49 & $29,9 \%$ & 104 & $63,4 \%$ & 2 & $1,9 \%$ & 0 & $0,0 \%$ & 20 & $19,2 \%$ & 82 & $78,8 \%$ & 1 & $1,7 \%$ & 8 & $13,3 \%$ & 29 & $48,3 \%$ & 22 & $36,7 \%$ \\
\hline 15 & 2 & $1,2 \%$ & 2 & $1,2 \%$ & 39 & $23,8 \%$ & 121 & $73,8 \%$ & 1 & $1,0 \%$ & 1 & $1,0 \%$ & 10 & $9,6 \%$ & 92 & $88,5 \%$ & 1 & $1,7 \%$ & 1 & $1,7 \%$ & 29 & $48,3 \%$ & 29 & $48,3 \%$ \\
\hline 16 & 1 & $0,6 \%$ & 7 & $4,3 \%$ & 40 & $24,4 \%$ & 116 & $70,7 \%$ & 1 & $1,0 \%$ & 3 & $2,9 \%$ & 16 & $15,4 \%$ & 84 & $80,8 \%$ & 0 & $0,0 \%$ & 4 & $6,7 \%$ & 24 & $40,0 \%$ & 32 & $53,3 \%$ \\
\hline
\end{tabular}


Para analisar os dados as afirmativas foram classificadas em 4 categorias de análise: 1- envolve as relações de trabalho; 2- relativo à qualificação dos profissionais farmacêuticos; 3- diz respeito à divisão de responsabilidades e 4relativo à função esperada de um farmacêutico.

Dentro da categoria 1 foram agrupadas as afirmativas 1, 3, 13 e 16. Quando se fala em interação interprofissional, seja ela durante a graduação ou dentro do ambiente de trabalho, é possível notar que a maioria dos alunos se mostra favorável $(79,3 \%, 75,0 \%, 83,5 \%$ e 70,7\%) (Tabela 3). A porcentagem de alunos que acredita que a interação interprofissional seja algo benéfico pode indicar que os estudantes sentem a necessidade de interação, e que conseguem projetar que a mesma é algo importante para o processo de formação e para o exercício profissional.

Já na categoria 2 (afirmativas 2, 4 e 7) (Tabela 3), ocorre uma diferença entre as opiniões dos estudantes. Os de Farmácia mostram maior confiança em sua educação do que os estudantes de Medicina na educação farmacêutica (afirmação 2; 53,8\% para os estudantes de Farmácia; $15,0 \%$ para os estudantes de Medicina). No que diz respeito à qualificação dos profissionais farmacêuticos para avaliar e responder às necessidades farmacoterapêuticas dos pacientes, há uma diferença significativa nas respostas quando os dois cursos são comparados. Para os estudantes de Farmácia, a maioria respondeu que concorda com a afirmação (concordo e concordo fortemente; 93,2\%), entretanto, para os alunos do curso de Medicina houve maior distribuição nas respostas entre discordo $(36,7 \%)$ e concordo $(45,0 \%)$. Tais respostas podem sugerir que os estudantes de Medicina não confiam completamente na qualificação dos farmacêuticos quanto à farmacoterapia. Cabe destacar também dentro deste grupo a afirmação 7: os estudantes dos dois grupos concordam que os farmacêuticos têm conhecimento especializado para aconselhar os pacientes sobre a farmacoterapia, porém, aproximadamente $20 \%$ dos estudantes de Medicina discordam.

A categoria 3 (afirmativas 5, 6, 8, 10, 11 e 14) (Tabela 3) apresentou respostas que sugerem que os estudantes de ambos os cursos, em sua maioria, concordam com o compartilhamento das responsabilidades. Há uma parcela significativa dos alunos de Medicina que discordam que os farmacêuticos deveriam ser os únicos responsáveis pelos medicamentos fornecidos aos pacientes 
(afirmação $5 ; 41,7 \%$ ). Uma possível interpretação deste resultado é que os estudantes de Medicina acreditam que essa responsabilidade deve ser compartilhada. Apesar desta diferença, as respostas mostram, de maneira geral, que os estudantes acreditam na divisão de responsabilidades no ambiente de trabalho, demonstrando confiança em seus colegas.

Dentro da categoria 4 (afirmativas 9, 12 e 15) (Tabela 3) ocorre uma diferença no padrão de respostas entre os dois cursos. Os estudantes do curso de Farmácia, em sua maioria, responderam com "concordo fortemente" (afirmativas 12 e 15) ou "discordo fortemente" (afirmativa 9), enquanto a opinião dos alunos de Medicina ficou dividida entre "concordo fortemente"/"concordo" para as afirmativas 12 e 15 e "discordo fortemente"/'discordo" para a afirmativa 9. Por meio da análise deste grupo, é possível levantar a questão de que os estudantes de Medicina não estão familiarizados com as funções do profissional farmacêutico e isso pode gerar um certo grau de desconfiança em suas atividades.

Analisando o grupo onde é abordada a questão da qualificação do profissional farmacêutico (grupo 2) é possível observar que os alunos de Medicina acreditam na qualificação deste profissional quando a mesma é utilizada para contribuir com o tratamento dos pacientes. Esta interpretação corrobora com o que é observado em relação ao grupo 1, em que os alunos demonstram acreditar em propostas interprofissionais e não em atendimento dos pacientes por um único profissional.

Um outro ponto importante a ser ressaltado, e que pode levar a uma explicação para as diferenças encontradas nas respostas dos estudantes dos dois cursos, é a própria estrutura geográfica da Universidade de São Paulo, onde o curso de Medicina encontra-se no quadrilátero da saúde, próximo ao metro Clínicas e ao Hospital das Clínicas, enquanto a Faculdade de Ciências Farmacêuticas está sediada na Cidade Universitária, zona oeste da cidade de São Paulo.

Além disso, ressalta-se que esse distanciamento é encontrado também dentro dos próprios hospitais da Universidade, ou seja, o Conselho Deliberativo (CD) do Hospital das Clínicas é formado apenas por médicos (HCFMUSP, 2018), enquanto que o CD do Hospital Universitário é formado pelos Diretores das Faculdades de Enfermagem, Medicina, Ciências Farmacêuticas, Odontologia e Psicologia, porém, 
segundo o estatuto, a presidência deve ser ocupada pelo Diretor da Faculdade de Medicina (SÃO PAULO, 2012).

Na Tabela 4 os dados estão representados como média, variância e desviospadrão. 
Tabela 4. Média das respostas (afirmações) dos estudantes segundo o curso de graduação.

\begin{tabular}{|c|c|c|c|c|c|c|c|c|c|}
\hline \multirow[b]{2}{*}{$\begin{array}{c}\text { Afirmações } \\
\text { (variáveis) }\end{array}$} & \multicolumn{3}{|c|}{ Farmácia $(n=104)$} & \multicolumn{3}{|c|}{ Medicina $(n=60)$} & \multicolumn{3}{|c|}{ Total $(n=164)$} \\
\hline & Média & Variância & $\begin{array}{l}\text { Desvio } \\
\text { padrão }\end{array}$ & Média & Variância & $\begin{array}{l}\text { Desvio } \\
\text { padrão }\end{array}$ & Média & Variância & $\begin{array}{l}\text { Desvio } \\
\text { padrão }\end{array}$ \\
\hline 1 & 3,9 & 0,17 & 0,41 & 3,5 & 0,56 & 0,75 & 3,7 & 0,35 & 0,59 \\
\hline 2 & 3,5 & 0,43 & 0,65 & 2,7 & 0,58 & 0,76 & 3,2 & 0,61 & 0,78 \\
\hline 3 & 3,8 & 0,23 & 0,48 & 3,6 & 0,34 & 0,59 & 3,7 & 0,28 & 0,53 \\
\hline 4 & 3,8 & 0,22 & 0,46 & 3,6 & 0,28 & 0,53 & 3,7 & 0,25 & 0,50 \\
\hline 5 & 3,4 & 0,47 & 0,68 & 2,7 & 0,67 & 0,82 & 3,1 & 0,66 & 0,81 \\
\hline 6 & 3,5 & 0,37 & 0,61 & 3,3 & 0,53 & 0,73 & 3,4 & 0,44 & 0,66 \\
\hline 7 & 3,5 & 0,48 & 0,70 & 3,0 & 0,61 & 0,78 & 3,3 & 0,58 & 0,76 \\
\hline 8 & 3,6 & 0,35 & 0,59 & 3,0 & 0,59 & 0,77 & 3,3 & 0,52 & 0,72 \\
\hline 9 & 1,2 & 0,13 & 0,36 & 1,6 & 0,35 & 0,59 & 1,3 & 0,25 & 0,50 \\
\hline 10 & 3,7 & 0,27 & 0,52 & 3,5 & 0,32 & 0,57 & 3,7 & 0,30 & 0,55 \\
\hline 11 & 3,6 & 0,40 & 0,63 & 3,0 & 0,75 & 0,86 & 3,4 & 0,60 & 0,78 \\
\hline 12 & 3,7 & 0,35 & 0,59 & 3,7 & 0,23 & 0,48 & 3,7 & 0,31 & 0,55 \\
\hline 13 & 3,9 & 0,19 & 0,43 & 3,7 & 0,21 & 0,45 & 3,8 & 0,20 & 0,45 \\
\hline 14 & 3,8 & 0,31 & 0,55 & 3,2 & 0,54 & 0,73 & 3,6 & 0,46 & 0,68 \\
\hline 15 & 3,9 & 0,20 & 0,45 & 3,4 & 0,39 & 0,62 & 3,7 & 0,31 & 0,56 \\
\hline 16 & 3,8 & 0,30 & 0,55 & 3,5 & 0,39 & 0,62 & 3,7 & 0,35 & 0,59 \\
\hline
\end{tabular}

Fonte: (1) Processado no IBM SPSS Statistics 22. 
Aplicando-se o Teste T-Student (Tabela 4) - de diferença do escore médio geral, obtida pelas respostas dos estudantes ao questionário para os dois grupos de curso de graduação, os resultados indicam que há diferença significante, ao nível de menos que $1 \%$ entre os dois grupos $(t=5,83 ;$ g.l. $=162$; Sig. $(2$-tailed $)=0,000)$.

Pelo teste de diferenças de variâncias, os resultados indicam que existe diferença significante entre os cursos, entre os alunos que participaram de atividades interprofissionais e entre gênero, mas não entre os anos que os estudantes frequentam (Tabela 5).

Tabela 5. Teste de médias (variável dependente: escore total obtido (totresp_m)). Análise de Variância

Variável dependente: escore total obtido (totresp_m)

\begin{tabular}{|c|c|c|c|c|c|c|c|}
\hline & Média & $\begin{array}{l}\text { Desvio } \\
\text { padrão }\end{array}$ & Mediana & $\mathbf{n}$ & $F(1)$ & Sig & \\
\hline \multicolumn{8}{|l|}{ Curso } \\
\hline Farmácia & 3,5 & ,35 & 3,56 & 104 & 34,02 & 0,00 & $* * *$ \\
\hline Medicina & 3,2 & ,38 & 3,22 & 60 & & & \\
\hline \multicolumn{8}{|l|}{ Gênero } \\
\hline Feminino & 3,5 & ,37 & 3,56 & 109 & 14,59 & 0,00 & $* * *$ \\
\hline Masculino & 3,2 & ,41 & 3,25 & 55 & & & \\
\hline \multicolumn{8}{|l|}{ Ano de Curso } \\
\hline $1^{\circ}$ e $2^{\circ}$ anos & 3,4 & ,45 & 3,50 & 51 & 1,15 & $0,32 \mathrm{r}$ & n.s. \\
\hline $3^{\circ}$ e $4^{\circ}$ anos & 3,3 & ,43 & 3,44 & 55 & & & \\
\hline $5^{\circ}$ e $6^{\circ}$ anos & 3,5 & ,31 & 3,50 & 58 & & & \\
\hline \multicolumn{8}{|c|}{ Participou de atividades interprofissionais } \\
\hline Não & 3,4 & ,41 & 3,56 & 106 & 4,39 & 0,04 & * \\
\hline Sim & 3,3 & ,38 & 3,31 & 58 & & & \\
\hline Total & 3,4 &, 40 & 3,50 & 164 & & & \\
\hline
\end{tabular}

Fonte: (1) Estatística F-Snedecor. ${ }^{* * *}$ : Significante a $1 \%$; * Significante a $5 \%$

(2) Processado no IBM SPSS Statistics 22.

Além da análise demográfica, os estudantes foram questionados sobre suas vivências interprofissionais, se já passaram por alguma destas vivências e qual foi a experiência. A distribuição das atividades realizadas pelos estudantes está descrita na Tabela 6, onde é possível observar que o Hospital Universitário da USP é a maior porta para a interação interprofissional dos estudantes da área de saúde na USP. 
Tabela 6. Distribuição dos participantes em atividades ou disciplinas.

\begin{tabular}{lcc|}
\hline Participou de alguma das atividades ou disciplinas & Farmácia & Medicina \\
\hline Estágio no Hospital Universitário (HU) & 13 & 22 \\
\hline Práticas, formação e educação interprofissional em Saúde & 6 & 0 \\
\hline $\begin{array}{l}\text { Estágio no HU e Práticas, formação e educação } \\
\text { interprofissional em Saúde }\end{array}$ & 1 & 1 \\
\hline Bandeira Científica & 1 & 6 \\
\hline Estágio na FARMUSP & 1 & 0 \\
\hline Estágio no Hospital Universitário (HU), Bandeira Científica & 1 & 4 \\
\hline JCAFB (Jornada Científica dos Acadêmicos de Farmácia- & 1 & 0 \\
Bioquímica) e JUS (Jornada Universitária da Saúde) & & 1 \\
\hline $\begin{array}{l}\text { Estágio no HU, Bandeira Científica e Práticas, formação e } \\
\text { educação interprofissional em Saúde }\end{array}$ & 0 & $\mathbf{3 4}$ \\
\hline Total & $\mathbf{2 4}$ & $\mathbf{3 4}$ \\
\hline
\end{tabular}

Nas Tabelas 7 e 8 estão apresentados os resultados relacionados às respostas dos estudantes de acordo com a sua participação em atividades interprofissionais.

Tabela 7. Respostas dos estudantes de acordo com a participação em atividades interprofissionais.

\begin{tabular}{c|cc|c|cc|c|}
\hline \multirow{2}{*}{$\begin{array}{c}\text { Afirmações } \\
\text { (variáveis) }\end{array}$} & \multicolumn{3}{|c|}{ Não (n=106) } & \multicolumn{3}{c|}{ Sim (n=58) } \\
\cline { 2 - 7 } & Média & Variância & $\begin{array}{c}\text { Desvio } \\
\text { padrão }\end{array}$ & Média & Variância & $\begin{array}{c}\text { Desvio } \\
\text { padrão }\end{array}$ \\
\hline 1 & 3,8 & 0,38 & 0,62 & 3,7 & 0,28 & 0,53 \\
2 & 3,4 & 0,52 & 0,72 & 2,9 & 0,63 & 0,80 \\
3 & 3,7 & 0,29 & 0,54 & 3,7 & 0,25 & 0,50 \\
4 & 3,8 & 0,24 & 0,49 & 3,7 & 0,26 & 0,51 \\
5 & 3,2 & 0,59 & 0,77 & 3,0 & 0,75 & 0,87 \\
6 & 3,4 & 0,48 & 0,69 & 3,4 & 0,38 & 0,62 \\
7 & 3,4 & 0,47 & 0,68 & 3,1 & 0,74 & 0,86 \\
8 & 3,5 & 0,37 & 0,61 & 3,1 & 0,68 & 0,83 \\
9 & 1,2 & 0,19 & 0,43 & 1,5 & 0,32 & 0,57 \\
10 & 3,7 & 0,32 & 0,56 & 3,6 & 0,28 & 0,52 \\
11 & 3,5 & 0,52 & 0,72 & 3,2 & 0,70 & 0,83 \\
12 & 3,7 & 0,37 & 0,61 & 3,7 & 0,20 & 0,44 \\
13 & 3,8 & 0,23 & 0,47 & 3,8 & 0,16 & 0,40 \\
14 & 3,6 & 0,41 & 0,64 & 3,4 & 0,52 & 0,72 \\
15 & 3,8 & 0,25 & 0,50 & 3,6 & 0,39 & 0,62 \\
16 & 3,7 & 0,40 & 0,63 & 3,7 & 0,27 & 0,52 \\
\hline
\end{tabular}


Tabela 8. Distribuição das respostas dos estudantes de acordo com sua participação em atividades interprofissionais.

\begin{tabular}{|c|c|c|c|c|}
\hline & $\begin{array}{l}1 \text { - Discordo } \\
\text { Fortemente }\end{array}$ & 2 - Discordo & 3 - Concordo & $\begin{array}{l}4 \text { - Concordo } \\
\text { Fortemente }\end{array}$ \\
\hline \multicolumn{5}{|l|}{ Não } \\
\hline 1 & $1,7 \%$ & $4,2 \%$ & $12,7 \%$ & $81,4 \%$ \\
\hline 2 & $0,8 \%$ & $12,7 \%$ & $36,4 \%$ & $50,0 \%$ \\
\hline 3 & $0,8 \%$ & $2,5 \%$ & $21,2 \%$ & $75,4 \%$ \\
\hline 4 & $0,8 \%$ & $0,8 \%$ & $19,5 \%$ & $78,8 \%$ \\
\hline 5 & $1,7 \%$ & $15,3 \%$ & $45,8 \%$ & $37,3 \%$ \\
\hline 6 & $1,7 \%$ & $5,9 \%$ & $39,8 \%$ & $52,5 \%$ \\
\hline 7 & $2,5 \%$ & $7,6 \%$ & $42,4 \%$ & $47,5 \%$ \\
\hline 8 & $1,7 \%$ & $5,1 \%$ & $39,8 \%$ & $53,4 \%$ \\
\hline 9 & $78,0 \%$ & $19,5 \%$ & $1,7 \%$ & $0,8 \%$ \\
\hline 10 & $0,8 \%$ & $2,5 \%$ & $28,0 \%$ & $68,6 \%$ \\
\hline 11 & $1,7 \%$ & $8,5 \%$ & $33,1 \%$ & $56,8 \%$ \\
\hline 12 & $0,8 \%$ & $5,1 \%$ & $18,6 \%$ & $75,4 \%$ \\
\hline 13 & $0,8 \%$ & $1,7 \%$ & $13,6 \%$ & $83,9 \%$ \\
\hline 14 & $1,7 \%$ & $3,4 \%$ & $25,4 \%$ & $69,5 \%$ \\
\hline 15 & $0,8 \%$ & $1,7 \%$ & $17,8 \%$ & $79,7 \%$ \\
\hline 16 & $0,8 \%$ & $5,9 \%$ & $22,9 \%$ & $70,3 \%$ \\
\hline \multicolumn{5}{|l|}{ Sim } \\
\hline 1 & $0,0 \%$ & $3,3 \%$ & $23,0 \%$ & $73,8 \%$ \\
\hline 2 & $3,3 \%$ & $29,5 \%$ & $45,9 \%$ & $21,3 \%$ \\
\hline 3 & $0,0 \%$ & $1,6 \%$ & $27,9 \%$ & $70,5 \%$ \\
\hline 4 & $0,0 \%$ & $1,6 \%$ & $29,5 \%$ & $68,9 \%$ \\
\hline 5 & $4,9 \%$ & $29,5 \%$ & $36,1 \%$ & $29,5 \%$ \\
\hline 6 & $0,0 \%$ & $6,6 \%$ & $50,8 \%$ & $42,6 \%$ \\
\hline 7 & $4,9 \%$ & $14,8 \%$ & $42,6 \%$ & $37,7 \%$ \\
\hline 8 & $4,9 \%$ & $14,8 \%$ & $49,2 \%$ & $31,1 \%$ \\
\hline 9 & $54,1 \%$ & $42,6 \%$ & $3,3 \%$ & $0,0 \%$ \\
\hline 10 & $0,0 \%$ & $1,6 \%$ & $34,4 \%$ & $63,9 \%$ \\
\hline 11 & $3,3 \%$ & $16,4 \%$ & $41,0 \%$ & $39,3 \%$ \\
\hline 12 & $0,0 \%$ & $0,0 \%$ & $26,2 \%$ & $73,8 \%$ \\
\hline 13 & $0,0 \%$ & $0,0 \%$ & $19,7 \%$ & $80,3 \%$ \\
\hline 14 & $1,6 \%$ & $8,2 \%$ & $37,7 \%$ & $52,5 \%$ \\
\hline 15 & $1,6 \%$ & $1,6 \%$ & $34,4 \%$ & $62,3 \%$ \\
\hline 16 & $0,0 \%$ & $1,6 \%$ & $32,8 \%$ & $65,6 \%$ \\
\hline
\end{tabular}

Fazendo a análise da mesma maneira em relação ao resultado geral é possível observar que há diferença nas respostas obtidas, comparando-se o grupo que participou de atividades interprofissionais com o grupo que não participou de nenhuma atividade (Tabela 8). 
Observando as afirmativas 1, 3, 13 e 16 (Tabela 8) nota-se que não há grande diferença nas respostas entre os dois grupos. Dentro do grupo que não participou de atividades interprofissionais é possível observar que há um entendimento de que o trabalho em equipe é necessário, porém há um número maior de estudantes que não concorda com a inclusão de atividades interprofissionais durante a graduação $(5,9 \%$, item 16$)$ em relação ao grupo que participou de atividades interprofissionais (1,6\%, item 16). Tal resultado pode ser atribuído à própria falta de exposição a esse tipo de metodologia de ensino ou mesmo pela falta de entendimento destes estudantes de como se dá esse processo, além dos resultados que ele pode trazer, tanto para a formação profissional, quanto para o próprio paciente que receberá o atendimento.

A análise do segundo grupo (afirmativas 2, 4 e 7) (Tabela 8) mostra que, de maneira geral, dentre os estudantes que participaram de atividades interprofissionais, há menor confiança na qualificação do profissional farmacêutico. Isso pode ser explicado por: 1. A maioria dos estudantes deste grupo corresponde a estudantes de Medicina e, como citado anteriormente, estes mostraram-se menos confiantes na educação farmacêutica; 2 . Estes estudantes já conviveram com outros profissionais e tiveram experiências consideradas ruins, uma vez que nem todas as atividades listadas (Tabela 6) possuem uma estruturação focada no aprendizado interprofissional e, muitas vezes, os alunos são apenas colocados para trabalharem juntos, sem nenhum preparo prévio ou entendimento do que é proposto e esperado. Além disso, é possível encontrar na literatura dados que mostram que os estudantes de Medicina são mais relutantes em relação a práticas interprofissionais (ŠEŠELJA PERIŠIN , 2015; KATOUE et al., 2017; VAN WINKLE et al., 2012).

Dentro do terceiro grupo (afirmativas 5, 6, 8, 10, 11 e 14) (Tabela 8) não foram encontradas diferenças entre os dois grupos. Já com a análise do grupo 4 (afirmativas 9, 12 e 15) é possível sugerir que os estudantes que passaram por atividades interprofissionais conseguem ter uma visão melhor das atribuições do profissional farmacêutico em relação aos demais estudantes. Além disso, demonstram também acreditar que é necessário haver conscientização dos profissionais médicos quanto ao conhecimento agregado sobre farmacoterapia que os farmacêuticos podem trazer. 
Aplicando-se o Teste T-Student (Tabela 7) - de diferença do escore médio geral, obtida pelas respostas dos estudantes ao questionário para os que participaram ou não das atividades interprofissionais, os resultados indicam que há diferença significante, ao nível de $1 \%$ entre os dois grupos $(t=2,096$; g.l.=162; Sig. $(2$-tailed $)=0,038)$. Esta diferença pode sugerir que estudantes que passam por experiências interprofissionais são mais propensos a confiar no trabalho de seus companheiros e também mais favoráveis ao trabalho em grupo.

Esse resultado corrobora com o obtido na Croácia, onde foi observada melhora significativa em relação às atitudes de colaboração entre médicos e farmacêuticos, em ambos os grupos de alunos, com mudanças mais marcantes observadas em estudantes de Medicina, após os estudantes serem submetidos a um workshop interprofissional de farmacologia durante um período de 3 horas (MODUN, 2015).

\section{CONCLUSÃO}

Os estudantes de Farmácia da USP apresentaram uma atitude mais positiva em ralação à colaboração médico-farmacêutico no presente estudo, o que poderia ter um efeito positivo sobre a colaboração interprofissional no futuro, quando estes alunos começarem a trabalhar como profissionais de saúde. Entretanto, futuros estudos, focados na promoção dessa colaboração, tanto em nível de graduação quanto de pós-graduação, são necessários.

As limitações deste estudo incluem a pesquisa em uma única instituição, a falta de heterogeneidade da amostra (a maioria das respostas foram de estudantes de Farmácia) e o número reduzido de respostas. Apesar destas limitações, os resultados são encorajadores e podem suportar a ideia de que os alunos das duas instituições estão abertos às experiências interprofissionais, ainda durante o decorrer de suas graduações. Mesmo assim, um estudo mais aprofundado e com uma amostra maior se faz necessário para poder investigar as razões possíveis para as diferenças encontradas entre os dois grupos avaliados quanto à participação em atividades interprofissionais. 


\section{REFERÊNCIAS}

BALDWIN D. Historical notes on interdisciplinary and interprofessional education and practice in the USA. J Interprof Care. 2007;21 (suppl 1):23-37.

BROCK K.A., DOUCETTE W.R. Collaborative working relationships between pharmacists and physicians: an exploratory study. J Am Pharm Assoc (Wash). 2004;44(3):358-365.

CUNHA, Luiza Correia. Colaboração entre farmacêuticos e médicos: uma revisão sistemática e validação de um instrumento de avaliação. 2016. 107 f. Dissertação (Mestrado) - Programa de Pós-graduação Ciências Farmacêuticas, Universidade Federal de Sergipe, São Cristóvão (SE), 2016. Disponível em: <https://bdtd.ufs.br/handle/tede/2885>. Acesso em: 06 out. 2016.

CUNHA L, NEVES S, MARQUES TC, ARAÚJO D, ALCANTARA T, LYRA DP Jr. Cross-cultural adaptation and validation to Brazil of the scale of attitudes toward physician-pharmacists collaboration. Pharmacy Practice 2017 AprJun;15(2):872.

DAVIES J.G., HORNE R., BENNETT J., STOTT R. Doctors, pharmacists and the prescribing process. Br J Hosp Med (Lond). 1994;52(4):167-170.

GOMES, Ligia Ferreira. Prática Multiprofissional em Atenção Básica à Saúde. Disponível em:

<https://uspdigital.usp.br/jupiterweb/obterDisciplina?sgldis=FBC0534\&verdis=2>. Acesso em: 12 maio 2018.

GONÇALVES, D. I. F. Pesquisas de marketing pela internet: As percepções sob a ótica dos entrevistados. Revista de Administração Mackenzie, V. 9, N. 7, Nov/Dez 2008.

HAXBY D.G., WEART C.W., GOODMAN BW Jr. Family practice physicians' perceptions of the usefulness of drug therapy recommendations from clinical pharmacists. Am J Hosp Pharm. 1988;45:824-7. 
HOSPITAL DAS CLÍNICAS DA FACULDADE DE MEDICINA DA USP (HCFMUSP) Administração Superior - Conselho Deliberativo. São Paulo, 2018. Disponível em: http://www.hc.fm.usp.br/index.php?option=com content\&view=article\&id=84\&ltemid= 215. Acesso em 14 jun 2018.

KATOUE MG, AWAD AL, AL-JARALLAH A, AL-OZAIRI E, SCHWINGHAMMER TL. Medical and pharmacy students' attitudes towards physician-pharmacist collaboration in Kuwait. Pharmacy Practice 2017 Jul-Sep;15(3):1029.

MCDONOUGH R.P., DOUCETTE W.R. Dynamics of Pharmaceutical Care: Developing Collaborative Working Relationships Between Pharmacists and Physicians. J Am Pharm Assoc. 2001;41(5) 682-692.

MINISTÉRIO DA EDUCAÇÃO. Resolução $n^{\circ}$ 3, de 20 de junho de 2014. Resolução $N^{\circ}$ 3, de 20 de junho de 2014: Institui as Diretrizes Curriculares Nacionais do Curso de Graduação em Medicina e dá outras providências. Brasília, DF: Diário Oficial da União, 23 jun. 2014. Seção 1, p. 8-11. Disponível em: <http://portal.mec.gov.br/index.php?option=com_docman\&view=download\&alias=15 874-rces003-14\&category_slug=junho-2014-pdf\&Itemid=30192>. Acesso em: 05 jun. 2018.

MINISTÉRIO DA EDUCAÇÃO. Resolução $\mathrm{n}^{\circ}$ 6, de 19 de outubro de 2017. Resolução $N^{\circ}$ 6, de 19 de Outubro de 2017: Institui as Diretrizes Curriculares Nacionais do Curso de Graduação em Farmácia e dá outras providências. Brasília, DF: Diário Oficial da União, 20 out. 2017. n. 202, Seção 1, p. 30. Disponível em: <http://portal.mec.gov.br/index.php?option=com_docman\&view=download\&alias=74 371-rces006-17-pdf\&category_slug=outubro-2017-pdf\&Itemid=30192>. Acesso em: 05 jun. 2018.

MODUN, DARKO. (2015). Interprofessional pharmacology workshop: intervention to close the gap between physicians' and pharmacists' attitudes toward their mutual collaboration. Intrinsic Activity. 3. A9.1. 10.25006/IA.3.S2A9.1. 
NERI, M. III Fórum das Diretrizes Curriculares. 22/09/2015. Disponível em: <http://portal.crfsp.org.br/noticias/6873-iii-forum-estadual-de-discussao-dasdiretrizes-curriculares.html>. Acesso em: 09 nov. 2015.

ORGANIZAÇÃO MUNDIAL DA SAÚDE. (1988). Learning together to work together for health. (série de relatórios técnicos 769). Genebra, Suíça. Disponível em: http://whqlibdoc.who.int/trs/WHO_TRS_769.pdf

ORGANIZAÇÃO MUNDIAL DA SAÚDE. Framework for action on interprofessional education \& collaborative practice. Genebra: OMS; 2010. Disponível em: <http://www.who.int/hrh/resources/framework_action/en/> Acesso em: 25 jul. 2014.

PEDUZZI M, NORMAN IJ, GERMANI ACCG, SILVA JAM, SOUZA GC. Educação interprofissional: formação de profissionais de saúde para o trabalho em equipe com foco nos usuários. Revista da Escola de Enfermagem da USP 2013; 47(4):977-83.

SÃO PAULO. JOÃO GRANDINO RODAS. (Ed.). RESOLUÇÃO № 6313, DE 06 DE JULHO DE 2012: Regimento do Hospital Universitário da Universidade de São Paulo. 2012. Disponível em: <http://www.hu.usp.br/regimento/>. Acesso em: 11 jul. 2012.

ŠEŠELJA PERIŠIN, A et al.: Interprofessional students' pharmacology workshop: intervention to improve health profession students' attitudes toward physician-pharmacist collaboration. Intrinsic Activity, 2015; 3(Suppl. 2):A9.2http://www.intrinsicactivity.org/2015/3/S2/A9.2 Publicado online : 9 set. 2015

SILVA, R. H. A. Educação interprofissional na graduação em saúde: aspectos avaliativos da implantação na Faculdade de Medicina de Marília (Famema) Educar em Revista, Curitiba: UFPR Ed., n. 39, p. 159-175, jan./abr, 2011. 
SWEENEY M.A. Physician-pharmacist collaboration: a millennial paradigm to reduce medication errors. J Am Osteopath Assoc. 2002;102(12):678-681.

VAN WINKLE L.J., FJORTOFT N., HOJAT M.. Validation of an instrument to measure pharmacy and medical students' attitudes toward physicianpharmacist collaboration. Am J Pharm Ed. 2011;75(9):Article 178.

VAN WINKLE L.J., et al American Journal of Pharmaceutical Education Interprofessional Workshop to Improve Mutual Understanding Between Pharmacy and Medical Students. Am J Pharm Educ. 2012;76(8).

VIEIRA, Henrique Corrêa; CASTRO, Aline Eggres de; SCHUCH JÚNIOR, Vitor Francisco. $O$ uso de questionários via e-mail em pesquisas acadêmicas sob a ótica dos respondentes. 2010. Disponível em: <http://www.pucrs.br/ciencias/viali/recursos/online/inquiries/O uso de questionários via e-mail em pesquisas acadêmicas sob a ótica dos.pdf>. Acesso em: 01 jun. 2018.

ZILLICH A.J., MILCHAK J.L., CARTER B.L., DOUCETTE W.R. Utility of a questionnaire to measure physician-pharmacist collaborative relationships. J Am Pharm Assoc (Wash). 2006;46(4):453-458. 


\section{Anexo I}

\section{ESCALA DE ATITUDES SOBRE COLABORACৃAO MÉDICO-FARMACÊUTICO}

INSTRUÇŌES: Por faror, indique o quanto você concorda ou dincorda com cada uma das seguirres afimaxçes circulando o numero aproprindo na escala de 4 poutos (um múmero maior na escala indica maior concordẑncia).

Gênero: [M] Masculino [F] Feminino. Idade (em anos):

Você é um: [1] Estudante de farmácia: [ ] $1^{\circ}$ ano [ ] $2^{\circ}$ ano [ ] $3^{\circ}$ ano[ [ $4^{\circ}$ ano[ [ ] $5^{\circ}$ ano

[2] Estudante de medicina: [ ] $1^{\circ}$ ano [ $2^{\circ}$ ano [ ] $3^{\circ}$ ano [ [ $4^{\circ}$ ano [ ] $5^{\circ}$ ano

[3] Farmactutlico(a): [] Drogarla [] Farmacla Hosptalar [] Outro

[4] Medlco[a): Especifcar a especlaldade primaria

\begin{tabular}{|c|c|c|c|c|c|}
\hline & & है है है है है & & $\frac{\text { है }}{\mathrm{g}}$ & है \\
\hline$I$ & 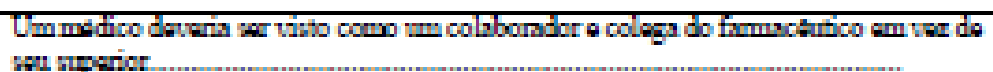 & 1 & 2 & 3 & 4 \\
\hline 2 & 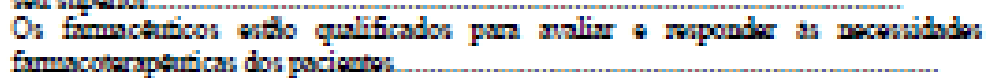 & 1 & 2 & 3 & \\
\hline 3 & 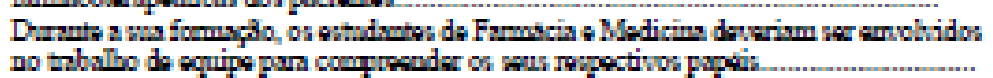 & 1 & 2 & 3 & \\
\hline 4 & 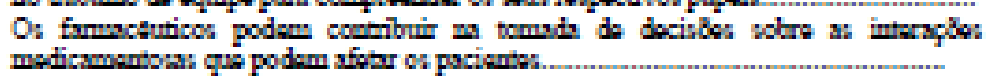 & 1 & 2 & 3 & \\
\hline 5 & 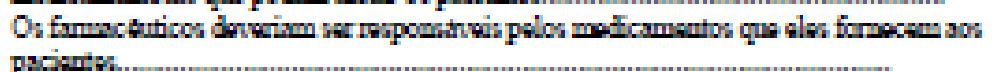 & 1 & 2 & 3 & \\
\hline 6 & 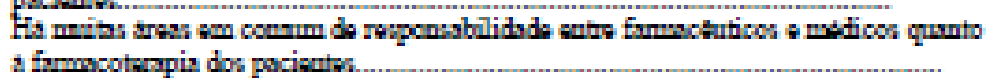 & 1 & 2 & 3 & \\
\hline 7 & 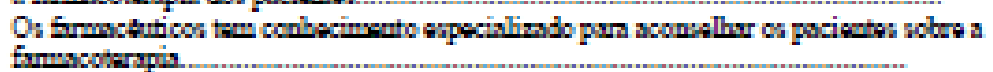 & 1 & 2 & 3 & \\
\hline 8 & 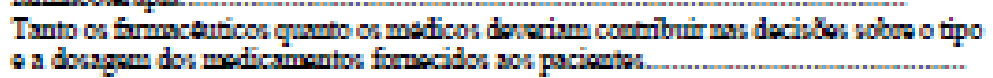 & 1 & 2 & 3 & \\
\hline 9 & 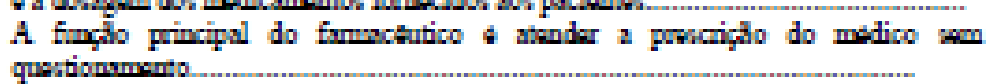 & 1 & 2 & 3 & \\
\hline 10 & 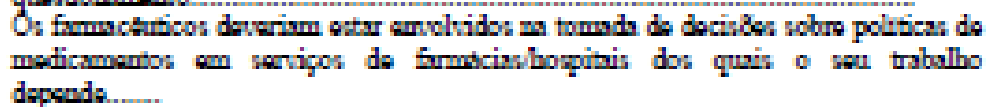 & 1 & 2 & 3 & \\
\hline 11 & 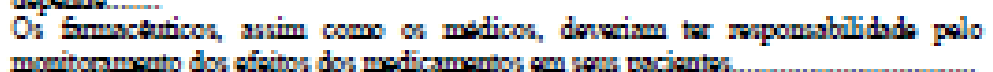 & 1 & 2 & 3 & \\
\hline 12 & 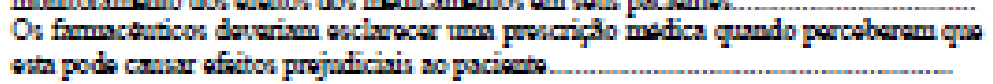 & 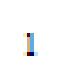 & 2 & 3 & \\
\hline 13 & 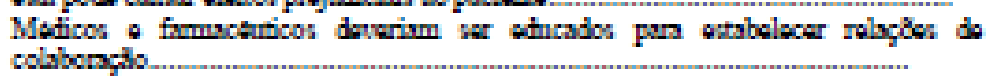 & 1 & 2 & 3 & \\
\hline 14 & 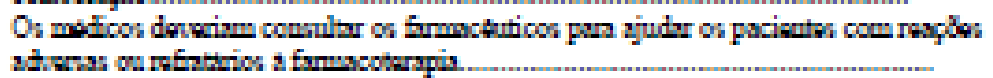 & , & 2 & 3 & \\
\hline 15 & 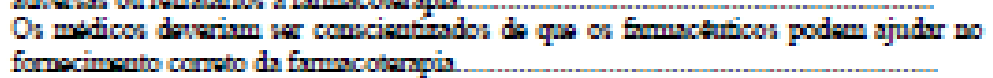 & 1 & 2 & 3 & \\
\hline 16 & 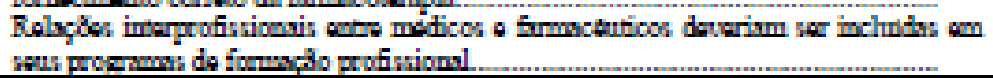 & 1 & 2 & 3 & \\
\hline
\end{tabular}




\section{UNIVERSIDADE DE SÃO PAULO \\ FACULDADE DE CIÊNCIAS FARMACÊUTICAS}

Cidade Universitária "Armando de Salles Oliveira"

05508-900 - Av. Prof. Lineu Prestes, 580 - São Paulo - Brasil

Caixa Postal 66083 - CEP 05315-970

\section{TERMO DE CONSENTIMENTO LIVRE E ESCLERECIDO}

\section{Informações sobre o Participante da Pesquisa}

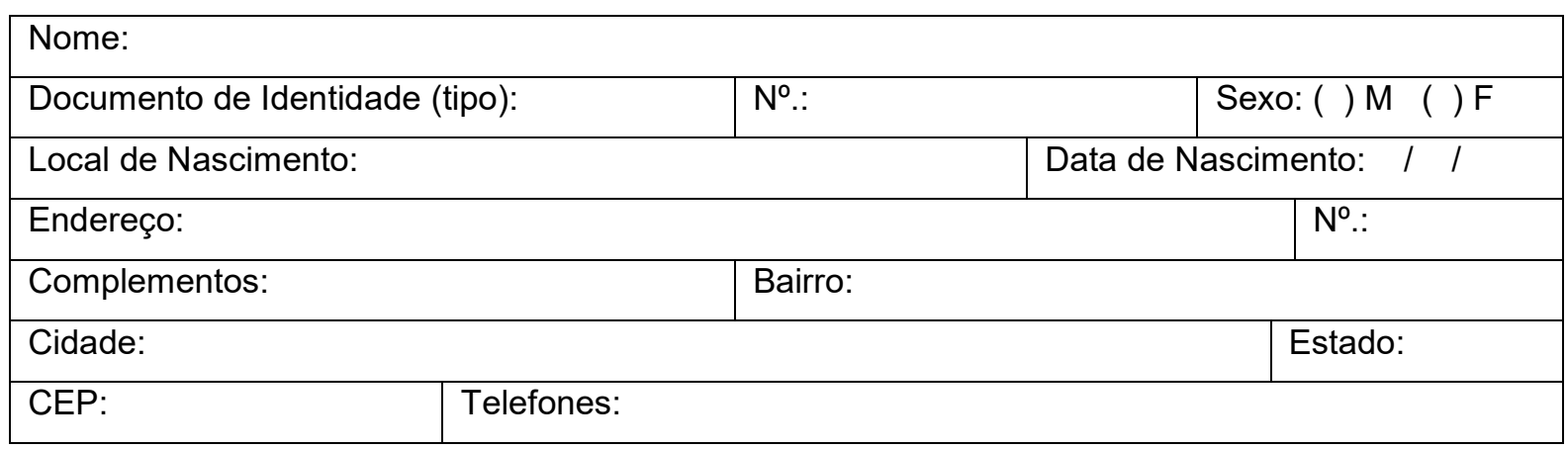

\section{Título do Projeto de Pesquisa}

Avaliação das atitudes de colaboração entre estudantes de graduação dos cursos de Farmácia e Medicina na Universidade de São Paulo

\section{Duração da Pesquisa}

Fevereiro a agosto de 2017

4. Nome do Pesquisador Responsável

Silvia Storpirtis

\begin{tabular}{|l|l}
\hline Cargo/ Função: Profa. Associada & $N^{\circ}$ de registro do Conselho Regional: CRF - 9794-8
\end{tabular}

\section{Instituição}

Faculdade de Ciências Farmacêuticas da Universidade de São Paulo e Secretaria de Estado da Saúde de São Paulo.

Vimos, por meio desta, solicitar formalmente sua participação voluntária na pesquisa intitulada "Avaliação das atitudes de colaboração entre estudantes de graduação dos cursos de Farmácia e Medicina na Universidade de São Paulo" que será realizada pela pesquisadora Milenna Castanho, aluna de mestrado do Programa de Fármaco e Medicamentos da Faculdade de Ciências Farmacêuticas da Universidade de São Paulo, sob orientação da professora Dra. Silvia Storpirtis 
(pesquisadora responsável), e que tem como objetivo avaliar o grau de cooperação entre estudantes de graduação dos cursos de Farmácia e Medicina da Universidade de São Paulo, Campus da Capital.

Você será esclarecido sobre a pesquisa em qualquer aspecto que desejar. Você é livre para se recusar a participar, retirar o seu consentimento ou interromper a participação a qualquer momento, independente de já haver iniciado sua colaboração. A sua participação é voluntária e a recusa em participar não irá acarretar qualquer penalidade ou perda de benefícios.

O pesquisador irá tratar a sua identidade com padrões profissionais de sigilo. O seu nome ou o material que identifique sua participação não será liberado sem sua permissão. Você não será identificado em nenhuma publicação que possa resultar deste estudo. Uma via deste consentimento informado será arquivada com os pesquisadores e outra será fornecida a você. A participação no estudo não acarretará custos para você e não será disponível nenhuma compensação financeira.

Abaixo seguem informações detalhadas sobre o projeto de pesquisa:

\section{a) Justificativa da pesquisa}

A prática farmacêutica vem, ao longo dos anos, mudando o seu foco, uma vez que as mudanças de perfil epidemiológico, como aumento da expectativa de vida, a diversidade de enfermidades crônicas, bem como a morbimortalidade associada ao uso de medicamentos e o aumento dos gastos com saúde, requerem acompanhamento prolongado de pacientes e requerem abordagem integral que contemple as múltiplas dimensões da assistência à saúde dos usuários e da população em geral, com ênfase em prevenção e educação em saúde . Atributos importantes dos profissionais de saúde incluem, mas não estão limitados a empatia cognitiva, a colaboração interprofissional, e orientações centradas no paciente. Instrumentos de pesquisa para medir cada um desses atributos foram projetados e validados em diferentes graus.

\section{b) Objetivos da pesquisa}

O objetivo deste trabalho é avaliar o grau de cooperação entre estudantes de graduação dos cursos de Farmácia e Medicina da Universidade de São Paulo, Campus da Capital.

São seus objetivos específicos:

- Aplicar o questionário via internet para os estudantes dos cursos de graduação em Farmácia e Medicina da Universidade de São Paulo, Campus São Paulo.

- Analisar os dados obtidos afim de avaliar qual a concepção dos estudantes em relação à cooperação médico-farmacêutico.

- Propor estratégias para superar as barreiras identificadas.

\section{c) Procedimentos}

Caso aceite participar do estudo ao aceitar este Termo de Consentimento Livre e Esclarecido, você será solicitado(a) a responder um questionário. Todo o processo deve levar em média 25 minutos para ser concluído, mas caso você não consiga responder tudo na hora, é possível continuar em outro momento, através do mesmo aparelho (computador, celular ou tablet) e link pois a pesquisa é salva automaticamente.

d) Desconforto e riscos esperados: 
O risco a que você será submetido é mínimo e, desta forma, não são esperados problemas de qualquer tipo durante sua participação.

\section{e) Informações de nomes, endereços e telefones dos responsáveis pelo acompanhamento da pesquisa:}

Caso apresente intercorrências ou para esclarecimento de quaisquer dúvidas, você pode entrar em contato com os responsáveis pelo acompanhamento da pesquisa:

- Pesquisadora responsável: Silvia Storpirtis; Telefone: (11) 2648-0674; Endereço: Rua da Praça do Relógio - no: 74 - Complemento: Centro de Vivência da Reitoria - Bairro: Cidade Universitária - Cidade: São Paulo/SP; E-mail: sstor@usp.br .

- Pesquisadora - Farmacêutica/Discente: Milenna Castanho; Telefone: (11) 96418-8875; Endereço: Rua dos Sorocabanos ～- n॰: 165 - Bairro: Ipiranga - Cidade: São Paulo/SP CEP: 04202-000; E-mail: milenna.castanho@usp.br .

\section{CONSENTIMENTO DE PARTICIPAÇÃO COMO JUÍZ ESPECIALISTA}

Declaro que, após ter sido convenientemente esclarecido pelo pesquisador e ter entendido o que me foi explicado, consinto em participar do presente Protocolo de Pesquisa.

São Paulo, de de

Para qualquer questão, dúvida, esclarecimento ou reclamação sobre aspectos éticos relativos a este protocolo de pesquisa, favor entrar em contato com o Comitê de Ética em Pesquisa da Faculdade de Ciências Farmacêuticas da Universidade de São Paulo: Av. Prof. Lineu Prestes, 580, Bloco 13 A, Butantã, São Paulo, CEP 05508-000, Telefones 3091-3622 e 3091-3677, e-mail: cepfcf@usp.br.

Observação: O TCLE deve ser rubricado em todas as páginas, pelo participante da pesquisa (ou seu responsável legal) e pelo pesquisador responsável. 


\section{Anexo III}

- Sistema Administrativo da Pós-Graduação

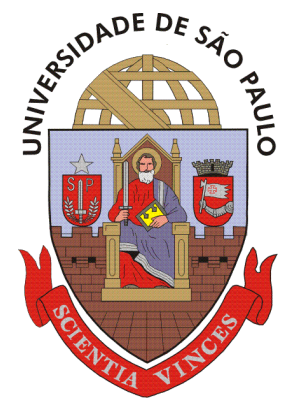

Universidade de São Paulo

Faculdade de Ciências Farmacêuticas

Documento sem validade oficial

FICHA DO ALUNO

9139 - 6828049/1 - Milenna Castanho

Email:

milenna.castanho@usp.br

Data de Nascimento:

27/05/1990

Cédula de Identidade:

RG - 49.340.369-3 - SP

Local de Nascimento:

Estado de São Paulo

Nacionalidade:

Brasileira

Graduação:

Farmacêutica-Bioquímica - Faculdade de Ciências Farmacêuticas Universidade de São Paulo - São Paulo - Brasil - 2015

\section{Curso:}

Mestrado

Programa:

Fármaco e Medicamentos

Área:

Data de Matrícula:

Produção e Controle Farmacêuticos

Início da Contagem de Prazo:

04/02/2016

Data Limite para o Depósito:

$04 / 02 / 2016$

Orientador:

$06 / 08 / 2018$

Proficiência em Línguas:

Prof(a). Dr(a). Silvia Storpirtis - 04/02/2016 até o presente. Email: sstor@usp.br

Inglês, Aprovado em 04/02/2016

Data de Aprovação no Exame de Qualificação:

Aprovado em 24/03/2017

Data do Depósito do Trabalho:

Título do Trabalho:

Data Máxima para Aprovação da

Banca:

Data de Aprovação da Banca:

Data Máxima para Defesa:

Data da Defesa:

Resultado da Defesa:

Histórico de Ocorrências:

Primeira Matrícula em 04/02/2016

Aluno matriculado no Regimento da Pós-Graduação USP (Resolução nº 6542 em vigor a partir de 20/04/2013).

Última ocorrência: Matrícula de Acompanhamento em 05/02/2018

Impresso em: 30/04/2018 16:44:02 


\begin{tabular}{|c|c|c|c|c|c|c|c|c|c|}
\hline Sigla & Nome da Disciplina & Início & Término & $\begin{array}{l}\text { Carga } \\
\text { Horária }\end{array}$ & Cred. & Freq. & Conc. & Exc. & Situação \\
\hline $\begin{array}{c}\text { FBF5777- } \\
3 / 6\end{array}$ & Tópicos Gerais de Fármaco e Medicamentos I & $10 / 03 / 2016$ & $30 / 06 / 2016$ & 45 & 3 & 93 & A & $\mathrm{N}$ & Concluída \\
\hline $\begin{array}{l}\text { FBF5779- } \\
2 / 4\end{array}$ & Preparo de Artigos Científicos na Área de Farmácia & $08 / 04 / 2016$ & 09/06/2016 & 90 & 0 & - & - & $\mathrm{N}$ & $\begin{array}{c}\text { Pré- } \\
\text { matrícula } \\
\text { indeferida }\end{array}$ \\
\hline $\begin{array}{l}\text { EDF5060- } \\
2 / 2\end{array}$ & $\begin{array}{l}\text { Transmissão Intergeracional, Educação e Trabalho (Faculdade } \\
\text { de Educaçẫo - Universidade de São Paulo) }\end{array}$ & $10 / 08 / 2016$ & $01 / 11 / 2016$ & 120 & 8 & 100 & A & $\mathrm{N}$ & Concluída \\
\hline $\begin{array}{l}\text { EDF5059- } \\
2 / 2\end{array}$ & $\begin{array}{l}\text { Identidades Profissionais Docentes: Representações, Saberes } \\
\text { e Práticas (Faculdade de Educação - Universidade de São } \\
\text { Paulo) }\end{array}$ & $11 / 08 / 2016$ & $02 / 11 / 2016$ & 120 & 8 & 75 & B & N & Concluída \\
\hline $\begin{array}{c}\text { EDF5108- } \\
1 / 1\end{array}$ & $\begin{array}{l}\text { Projetos de Vida, Cidadania e Educaçãa (Faculdade de } \\
\text { Educação - Universidade de São Paúlo) }\end{array}$ & $11 / 08 / 2016$ & $02 / 11 / 2016$ & 120 & 8 & 75 & A & $\mathrm{N}$ & Concluída \\
\hline
\end{tabular}

\begin{tabular}{|l|ccc|}
\hline & \multicolumn{2}{|c|}{ Créditos mínimos exigidos } & Créditos obtidos \\
\hline & Para exame de qualificação & Para depósito da dissertação & \\
\hline Disciplinas: & 0 & 25 & 27 \\
\hline Estágios: & & 25 & 27 \\
\hline Total: & 0 & 25 & \\
\hline
\end{tabular}

Créditos Atribuidos à Dissertação: 71

Última ocorrência: Matrícula de Acompanhamento em 05/02/2018

Impresso em: 30/04/2018 16:44:02 


\title{
Avaliação das atitudes de colaboração entre estudantes de graduação dos cursos de Farmácia e Medicina na Universidade de São Paulo
}

\author{
Questionário para a projeto de mestrado de Milenna Castanho
}

*Obrigatório

\section{INFORMAÇÕES PARA O PARTICIPANTE INFORMAÇÕES PARA O PARTICIPANTE}

\begin{abstract}
Você está sendo convidado(a) a participar de um estudo. Antes de tomar sua decisão, é importante que você entenda o porquê desta pesquisa e o que envolverá. Por favor, reserve algum tempo para ler as seguintes informações atentamente e sinta-se à vontade para entrar em contato conosco se quiser mais informações ou se tiver alguma dúvida. É necessário enfatizar que você não é obrigado(a) a aceitar este convite e deve participar apenas se quiser.
\end{abstract}

\section{Objetivos do estudo}

O objetivo deste trabalho é avaliar o grau de cooperação entre estudantes de graduação dos cursos de Farmácia e Medicina da Universidade de São Paulo, Campus da Capital. Esta pesquisa faz parte do mestrado de autoria de Milenna Castanho (Mestranda na Faculdade de Ciências Farmacêuticas da Universidade de São Paulo), sob orientação da Prof. ${ }^{a}$ Dr. ${ }^{a}$ Silvia Storpirtis (Docente da Faculdade de Ciências Farmacêuticas da Universidade de São Paulo) e colaboração da Prof. ${ }^{a}$ Dr. ${ }^{a}$ Ana Claudia Germani (Docente da Faculdade de Medicina da Universidade de São Paulo)

Por que eu deveria participar?

Sua participação é muito importante, vai nos ajudar a entender melhor a concepção dos estudantes de graduação dos cursos de Farmácia e Medicina na Universidade de São Paulo, Campus São Paulo, com relação ao grau de cooperação médico-farmacêutico, de modo a colaborar com as reflexões sobre o oferecimento de atendimento melhor e mais completo, focado nas necessidades dos usuários do Sistema Único Saúde.

Sua participação será muito importante para nós! Agradecemos também se puder ajudar-nos a divulgar para todos os seus amigos e contatos!

\section{Descrição e riscos do estudo}

Caso aceite participar do estudo ao aceitar este Termo de Consentimento Livre e Esclarecido, você será solicitado(a) a responder um questionário. Todo o processo deve levar em média 10 minutos para ser concluído, mas caso você não consiga responder tudo na hora, é possível continuar em outro momento, através do mesmo aparelho (computador, celular ou tablet) e link pois a pesquisa é salva automaticamente.

Completada a sua participação, e caso queira obter mais informações sobre o projeto, ou receber um relatório com os principais resultados que forem encontrados, favor entrar em contato com o pesquisador responsável através do email: milenna.castanho@usp.br.

Pediremos que você forneça alguns de seus dados sociodemográficos, além de responder o questionário.

Quanto aos riscos envolvidos com a participação na pesquisa, são mínimos.

Sigilo e Divulgação de Informações

Todas as suas respostas serão armazenadas de forma anônima e segura. Os resultados serão analisados quantitativamente de forma global e os resultados gerais divulgados de forma coletiva em forma de apresentação em congressos e/ou artigos científicos.

Você também pode interromper sua participação a qualquer momento e seus dados não serão utilizados durante as análises.

Caso tenha dúvidas, preocupações após sua participação, ou queira receber uma cópia deste Termo de Consentimento, entre em contato com Milenna Castanho (milenna.castanho@usp.br) ou Professora Dr. ${ }^{a}$ Silvia Storpirtis (sstor2011@gmail.com) ou pelo telefone (11) 96418-8875.

Não existem respostas "certas" ou "erradas". Também pedimos que responda da forma mais sincera, espontânea e honesta possível. 
A participação neste estudo é completamente voluntária e você está livre para desistir a qualquer momento.

Para esclarecimentos com relação às dúvidas éticas do projeto, pode-se também entrar em contato com o Comitê de Ética em Pesquisa com Seres Humanos da Faculdade de Ciências Farmacêuticas da Universidade de São Paulo, localizado na Av. Professor Lineu Prestes, 580 - Bloco 13A, CEP 05508-000 - Cidade Universitária - São Paulo/SP E-mail: cepfcf@usp.br - Telefone: (11) 3091-3622 ou 3091-3677.

1. Seu consentimento: eu declaro estar informado(a) das condições de participação na pesquisa " Avaliação das atitudes de colaboração entre estudantes de graduação dos cursos de Farmácia e Medicina na Universidade de São Paulo " e ter livre interesse em participar. Declaro também estar informado de todas as condições para participação. Eu reconheço que minha participação é anônima e as minhas informações fornecidas serão estritamente confidenciais e usadas apenas para fim de pesquisa científica. *

Marcar apenas uma oval.

Aceito

Não aceito Pare de preencher este formulário.

\section{Dados demográficos}

Por gentileza, fornecer os dados tomando como base a data de preenchimento do questionário

2. Gênero *

Marcar apenas uma oval.

Feminino

Marculino

Prefiro não dizer

3. Idade *

\section{Curso de Graduação *}

Marcar apenas uma oval.
Farmácia
Medicina

\section{Ano do curso *}

Marcar apenas uma oval.
$1^{\circ}$ ano
$2^{\circ}$ ano
$3^{\circ}$ ano
$4^{\circ}$ ano
$5^{\circ}$ ano
$6^{\circ}$ ano

6. Número USP *

\section{Experiência com educação interprofissional}


Educação Interprofissional em saúde: segundo a OMS, é observada quando estudantes de duas ou mais profissões aprendem sobre os outros, com os outros e entre si para possibilitar a colaboração eficaz e melhorar os resultados na saúde

7. Você já participou de alguma das atividades ou disciplinas abaixo? * Marque todas que se aplicam.

Estágio no Hospital Universitário (HU)

Bandeira Científica

Disciplina "Práticas, formação e educação interprofissional em Saúde" (antiga "Educação Interprofissional em saúde"

JCAFB (Jornada Científica dos Acadêmicos de Farmácia-Bioquímica)

JUS (Jornada Universitária da Saúde)

Não

\section{ESCALA DE ATITUDES SOBRE COLABORAÇÃO MÉDICO- FARMACÊUTICO}

INSTRUÇÕES: Por favor, indique o quanto você concorda ou discorda com cada uma das seguintes afirmações circulando o número apropriado na escala de 4 pontos (1- Discordo fortemente, 2-

Discordo, 3-Concordo, 4-Concordo fortemente). 
8. *

Marcar apenas uma oval por linha.

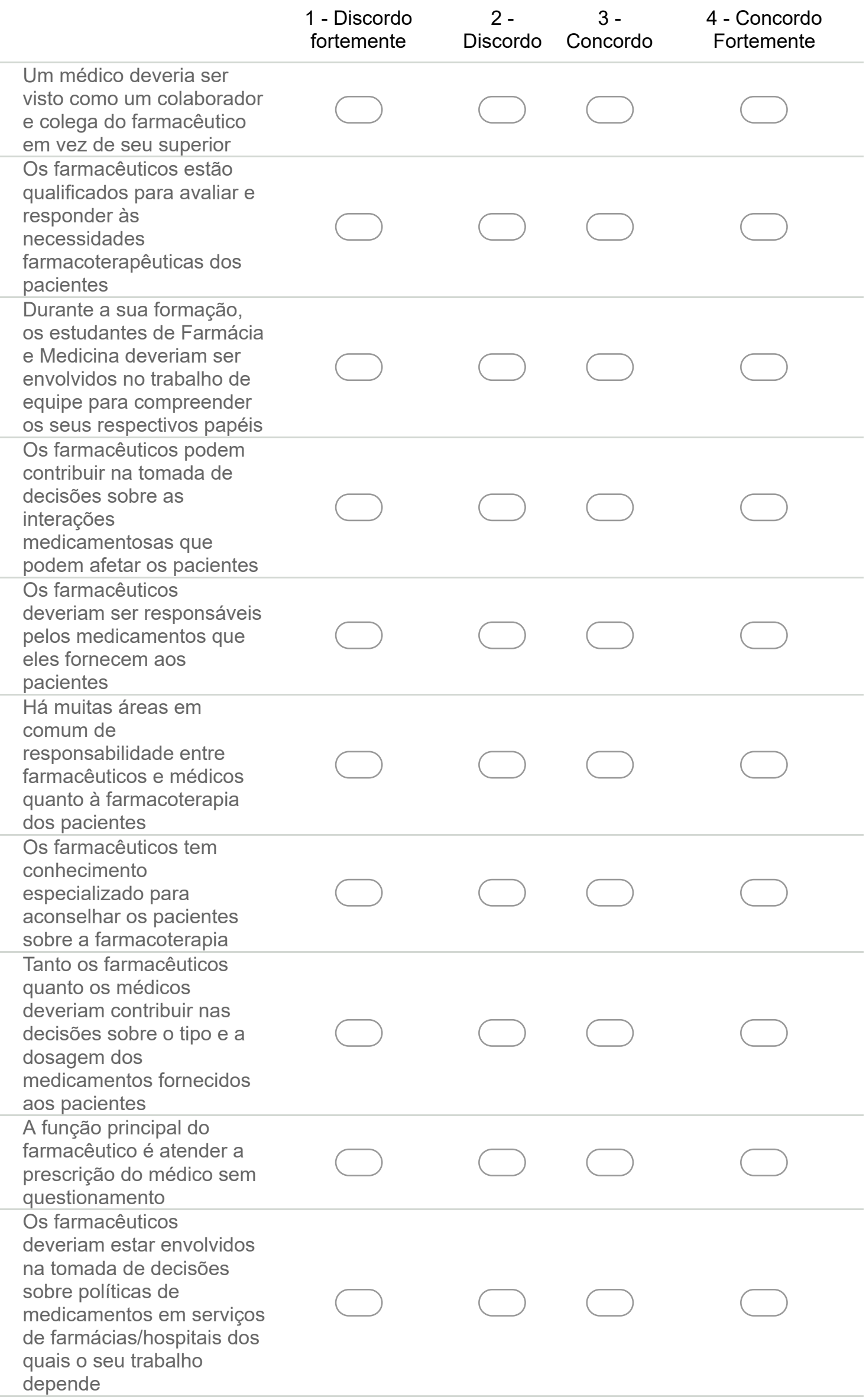


1 - Discordo

fortemente

Os farmacêuticos, assim

como os médicos,

deveriam ter

responsabilidade pelo

monitoramento dos efeitos

dos medicamentos em

seus pacientes

Os farmacêuticos

deveriam esclarecer uma

prescrição médica quando

perceberem que esta pode

causar efeitos prejudiciais

ao paciente

Médicos e farmacêuticos

deveriam ser educados

para estabelecer relações

de colaboração

Os médicos deveriam

consultar os farmacêuticos

para ajudar os pacientes

com reações adversas ou

refratários à

farmacoterapia

Os médicos deveriam ser

conscientizados de que os

farmacêuticos podem

ajudar no fornecimento

correto da farmacoterapia

Relações interprofissionais

entre médicos e

farmacêuticos deveriam

ser incluídas em seus

programas de formação profissional
2 -

Discordo Concordo

4 - Concordo

Fortemente

profissional

\section{Powered by}

: Google Forms 